\title{
Evaluating surface eddy properties in coupled climate simulations with 'eddy- present' and 'eddy-rich' ocean resolution
}

Article

Accepted Version

Creative Commons: Attribution-Noncommercial-No Derivative Works 4.0

Moreton, S. M., Ferreira, D., Roberts, M. J. and Hewitt, H. T. (2020) Evaluating surface eddy properties in coupled climate simulations with 'eddy-present' and 'eddy-rich' ocean resolution. Ocean Modelling, 147. 101567. ISSN 1463-5003 doi: https://doi.org/10.1016/j.ocemod.2020.101567 Available at https://centaur.reading.ac.uk/88390/

It is advisable to refer to the publisher's version if you intend to cite from the work. See Guidance on citing.

To link to this article DOI: http://dx.doi.org/10.1016/j.ocemod.2020.101567

Publisher: Elsevier

All outputs in CentAUR are protected by Intellectual Property Rights law, including copyright law. Copyright and IPR is retained by the creators or other copyright holders. Terms and conditions for use of this material are defined in the End User Agreement.

www.reading.ac.uk/centaur 
Central Archive at the University of Reading

Reading's research outputs online 
Evaluating surface eddy properties in coupled climate simulations with 'eddy-present' and 'eddyrich' ocean resolution

\section{Sophia Moreton (1), David Ferreira (1), Malcolm Roberts (2) and Helene Hewitt (2)}

(1) Department of Meteorology, University of Reading, Reading, UK

(2) Met Office Hadley Centre, Fitzroy Road, Exeter, Devon, UK

Correspondence: s.moreton@pgr.reading.ac.uk.

Postal Address: Sophia Moreton, Department of Meteorology, University of Reading, Earley Gate, PO Box 243, Reading, RG6 6BB, UK

\section{Highlights}

- Eddy-rich (ER) has smaller and longer-lasting eddies than eddy-present (EP)

- EP captures $40 \%$ of eddies in observations even at high latitudes (ER captures 63\%)

- Both model resolutions have a low eddy count in the EBUS and gyre interiors

- Eddy radii scale well with the minimum of the Rossby radius or the Rhines Scale

Keywords Mesoscale eddies; Eddy properties; High resolution coupled global model; Eddy dynamics Abstract

As climate models move towards higher resolution, their ocean components are now able to explicitly resolve mesoscale eddies. High resolution for ocean models is roughly classified into eddy-present $\left(E P, \sim 1 / 4^{\circ}\right)$ and eddy-rich $\left(E R, \sim 1 / 12^{\circ}\right)$ resolution. The cost-benefit of ER resolution over EP resolution remains debated. To inform this discussion, we quantify and compare the surface properties of coherent mesoscale eddies in high-resolution versions of the HadGEM3-GC3.1 coupled climate model, using an eddy tracking algorithm. The modelled properties are compared to altimeter observations. Relative to EP, ER resolution simulates more $(+60 \%)$ and longer-lasting $(+23 \%)$ eddies, in better agreement with observations. The representation of eddies in Western Boundary Currents (WBC) and the Southern Ocean compares well with observations at both resolutions. However a common deficiency in the models is the low eddy population in subtropical gyre interiors, which reflects model biases at the Eastern Boundary Upwelling Systems and at the Indonesian outflow, where most of these eddies are generated in observations. Despite a grid spacing larger than the Rossby radius of deformation at high-latitudes, EP resolution does allow for eddy growth in these regions, although at a lower rate than seen in observations and ER resolution. A key finding of our analysis is the large differences in eddy size across the two resolutions and observations: the median speed-based radius increases from $14 \mathrm{~km}$ at ER resolution to $32 \mathrm{~km}$ at EP resolution, compared with $48 \mathrm{~km}$ in observations. It is likely that observed radii are biased high by the effective resolution of the gridded altimeter dataset due to post-processing. Our results highlight the limitations of the altimeter products and the required caution when employed for understanding eddy dynamics and developing eddy parameterizations. 


\section{Introduction}

Mesoscale ocean eddies, generated from baroclinic and barotropic instabilities of the mean flow, are ubiquitous in the world oceans [16]. Ocean eddies are important for a number of local processes such as air-sea exchanges of momentum, freshwater and heat fluxes $[60,61,33,82]$ and the upwelling of nutrients, which promotes biological activity [30,8]. Mesoscale eddies have a major influence on the large-scale circulation, controlling its mean state in the Antarctic Circumpolar Current [52], as well as its response to climate change [e.g. 2, 58, 34].

Over the last decade or so, many climate modelling groups have sought to increase the resolution of ocean models [e.g. 55, 34, 67]. The primary aim has been to improve the representation of key mesoscale features such as eddies, boundary currents and narrow sills (for dense overflows), and hence improve the mean-state and variability of the coupled climate system $[64,57,53]$. It remains unclear whether the improved model fidelity in higher resolution models is primarily a result of an improved mean state via these key frontal features, or a consequence of the improved representation of the eddies themselves. The computational expense of a highresolution ocean component in a coupled climate model is high and the benefits of increased computational cost need to be clearly identified.

In this context, the "high resolution" ocean component often refers to two types of resolutions: eddypresent $\left(\mathrm{EP}, \sim 1 / 4^{\circ}\right.$ ) and eddy-rich $\left(\mathrm{ER}, \sim 1 / 12^{\circ}\right.$ ) [27]. Although not strictly defined, EP denotes resolutions which permit some mesoscale eddies to be captured in the low and mid-latitudes, while ER refers to resolution for which eddies are present at most latitudes (excluding the Arctic basin and the continental shelf around Antarctica). The distribution of mesoscale features in a model mainly depends on the ratio of its horizontal grid resolution, $\Delta x$, to the Rossby radius of deformation, $R_{d}$. Barotropic and baroclinic instability processes are only expected to be properly resolved when the grid point spacing $\Delta x$ is several times smaller than $R_{d}$, although a minimal criteria of 2 times smaller has sometimes been used [37].

Although coupled models with a high-resolution ocean component are increasingly available, many modelling centres have not yet developed an operational version of their climate models with a high-resolution ocean component. The upcoming Coupled Model Inter-comparison Project (CMIP6) will encompass models across a range of resolutions, including EP and ER resolutions (CMIP6 HighResMIP) as well as eddy-parameterising models $[25,36]$. The cost-benefit balance of ER versus EP resolution is still being examined. While EP offers a lower computational cost than ER resolution, it sits in the so-called 'grey-zone' where the benefits of removing eddy parameterization and resolving some (but not all) mesoscale eddies and eddy fluxes are not obviously superior to a coarser resolution ocean with full eddy parameterization [40]. Although the mesoscale field comprises more than just coherent eddies, evaluating the representation of coherent eddies at EP and ER resolutions can inform the choice of resolution in future model development $[40,77]$.

Understanding the properties of eddies is also essential for their parameterization in coarse ocean models [32]. For example, the eddy scale (estimated from either observations or models) often explicitly enters eddy parameterization schemes through mixing length arguments e.g.[23,6]. The size of coherent mesoscale eddies 
is often used as an indicator of scale for the whole mesoscale field and is a fundamental measure employed in numerous studies of eddy dynamics, notably to distinguish dynamical regimes $[79,78,22,75,46]$.

While ocean models are not perfect tools to provide estimates of eddy properties, the robustness of the spatial and temporal eddy scales from satellite altimetry has been questioned [13, 14, 17, 22]. Distortion of the data can occur through the smoothing and interpolation required to generate a gridded product from raw satellite measurements. Whilst high-resolution altimeters are currently being developed e.g. the future Surface Water Ocean Topography (SWOT) mission, numerical simulations can allow us to evaluate eddy properties at a much higher resolution than currently possible through observations $[44,80]$.

To date eddy properties have been studied in (coupled or ocean-only) high-resolution models at a regional scale. Particular regions of interest include the Agulhas eddy pathways, important for heat transfer into the South Atlantic [55], and the Californian Current System where eddies play a role in the transfer of heat and nutrients from upwelling systems into the open ocean $[48,28]$. Here we present a first global assessment of mesoscale eddy properties (e.g. distribution, size, speed and lifetime) in two versions of the coupled model HadGEM3-GC3.1 with EP and ER ocean resolution. Our study focuses on the field of coherent mesoscale vortices, defined by closed sea surface height (SSH) contours, rather than the general mesoscale field comprising filaments and unclosed structures. The characteristics (e.g. eddy kinetic energy, heat transport) of the two fields likely differs [e.g. 74, 71]. We will address three central questions in this study: 1 . As ocean resolution in coupled models is increased, how does the representation of eddies and their properties change? 2. How do modelled eddies and their properties compare to observations? 3. How do modelled eddies compare to theoretical predictions?

This paper is organised as follows. Section 2 describes the eddy detection algorithm, and the model outputs and observational datasets used. Section 3 presents results of global eddy counts and properties. Section 4 concludes and discusses the wider implications of the results.

\section{Method and Data}

\subsection{Eddy Detection Algorithm}

In this study, we use an eddy detection algorithm adapted from [54] (itself based on [14]). Eddies are identified and tracked as closed coherent vortices detected through successive closed contours of SSH anomalies, subject to various tests. The SSH field has a long-term 20 year mean removed. Large-scale SSH variability is removed using a Gaussian filter with widths of $20^{\circ} \times 10^{\circ}$ (zonal $\times$ meridional). The differences between this algorithm and the original eddy detection algorithm of [14] are discussed in [54]. For example, this algorithm uses interpolated SSH contours instead of raw SSH pixels, it includes a 'shape test' (to test how circular the closed contour of SSH is) and a test for one local SSH minimum/maximum per eddy. Although the elongation of eddy shape can play a role in the strength and extent of Western Boundary Currents (WBC), it is excluded from this study [84]. Details of the scheme, criteria and tracking along with our adaptations of the filtering and detection 
algorithm are further discussed in Appendix 1.

For both models and observations, the eddies are tracked globally using 20 years of daily SSH anomalies. We only consider eddies with a minimum lifetime of 7 days. To minimize noise, the maps and probability density functions (pdfs) of eddy statistics shown below only use eddies lasting longer than 1 month (unless otherwise specified). Eddy properties considered in this study are as follows [14, 54]. The effective radius, $L_{e f f}$, is defined as the radius of a circle with the same area as the area within the outermost closed SSH contour (satisfying all other criteria). The speed-based radius, $L_{s p d}$, is taken as the radius of a circle similarly fitted to the SSH contour with maximum averaged geostrophic velocity, $U$. By definition, $L_{s p d}$ is smaller than $L_{e f f}$ and [14] found that typically $L_{s p d} \simeq 0.7 L_{e f f}$. Eddy amplitude, $A$, is the absolute difference between the maximum (for anti-cyclones) or minimum (cyclones) SSH within the eddy and the SSH value of the outermost closed SSH contour (same contour as that used to define $L_{e f f}$ ). The propagation velocity $C_{g}^{e d d y}$ is computed from the daily displacements of the eddy center (defined as the center of a fitted circle to the smallest SSH contours, i.e. 8 pixels). Here, we focus on the zonal component of $C_{g}^{e d d y}$ computed from the zonal displacements only. Finally, a measure of eddy non-linearity is the ratio of the eddy rotational velocity to the eddy propagation velocity, $r=U / C_{g}^{e d d y}$. A value of $r$ greater than 1 suggests that fluid parcels are trapped within an eddy [14].

There are numerous eddy detection algorithms available in the literature $[86,73,49,1,15,26,29,59]$. They differ by the metric used for eddy identification (such as vorticity, Okubo-Weiss parameter or Lagrangian particle tracking), filtering or the tracking technique (for example to include the merging and splitting of eddy trajectories). Each method has its own advantages and limitations. The basis of this algorithm is physicallybased and has been heavily tested and used in literature [14]. In comparison to Lagrangian methods for example, Eulerian tracking methods (such as closed SSH contours employed here) tend to over-estimate material conservation and transport, see $[14,1,74]$. However, a comparison of surface eddy properties is carried out here instead of a quantification of eddy transport and energy. Crucially, in this study, the same eddy detection algorithm is used on all datasets (model outputs and altimeter observations) to eliminate differences arising from different detection algorithms.

\subsection{Coupled Model Configuration and outputs}

Outputs are analysed from the coupled high-resolution global climate model HadGEM3-GC3.1 [85]. This model comprises a GA7.1/GL7.1 atmosphere/land configuration based on the MetUM and JULES [83], a GO6 ocean [70] based on NEMO [50] and GSI8 sea ice based on CICE [62]. Two resolutions of the ocean component, both coupled to the same atmospheric component at resolution N216 ( $\sim 60 \mathrm{~km}$ at mid-latitudes), are compared: ORCA025 $\left(\sim 1 / 4^{\circ}\right.$, hereafter $\left.E P_{\text {sim }}\right)$ and ORCA12 $\left(\sim 1 / 12^{\circ}\right.$, hereafter $\left.E R_{\text {sim }}\right)$. The ocean components do not employ any eddy parameterizations other than a small amount of isopycnal mixing to control grid-scale noise. For further information about the model set-up, the reader is referred to [39, 85, 70].

The model simulations follow the CMIP6 HighResMIP protocol [36] with implementation described in [63]. Model outputs (20 years of daily mean SSH) are obtained after a 20 year spin-up. Although the large-scale 
continues to drift, it is likely that this has a negligible effect on eddy statistics, as changes in the background state are relatively small. In order to facilitate the comparison between versions of the coupled model, the eddy detection algorithm is also applied to 10 years of $E R_{\text {sim }}$ SSH output re-gridded onto the $E P_{\text {sim }}$ grid $\left(\sim 1 / 4^{\circ}\right)$ (hereafter $E R_{\text {sim }}$ regrid). The re-gridding was performed by bilinear interpolation, using an Earth System Modelling Framework (ESMF) [24], to generate conservative remapping of surface ocean variables (such as $\mathrm{SSH})[39,42]$.

\subsection{Observational data}

Observational SSH is taken from the gridded AVISO altimeter dataset (Archiving, Validation and Interpolating of Satellite Oceanographic Data, 2014; [21]). The Ssalto/Duacs altimeter products were produced and distributed by the Copernicus Marine and Environment Monitoring Service (CMEMS) (http://www.marine.copernicus.eu). The dataset provides daily SSH anomalies at $\sim 1 / 4^{\circ}$ resolution after the removal of a 20 -yr mean. The gridded SSH field is generated through optimal interpolation from the delayed-time merging of multiple satellites. Note that, because we use an updated gridded altimeter product as well as a modified eddy tracking algorithm, our observed eddy statistics will differ from those published by [14]

Comparison of the raw daily SSH variances reveals differences before applying any filtering or eddy tracking, notably between observations and $E P_{\text {sim }}$. Although it captures the observed pattern correctly, $E P_{\text {sim }}$ underestimates the magnitude of the observed variance, notably in WBC (not shown). $E R_{\text {sim }}$, however, compares reasonably well with observations on a global scale. Similar conclusions are obtained when comparing surface Eddy Kinetic Energy (not shown)

\section{Results}

We re-emphasize that the eddies detected in both observations and the model mostly consist of non-linear mesoscale coherent vortices in geostrophic balance. Most eddies in the $E R_{\text {sim }}, E P_{\text {sim }}$ and observations have a small Rossby number $R_{o}\left(=\frac{U}{f L_{s p d}}\right)$ : only $0.5,0.06$ and $0.09 \%$ of eddies in $E R_{\text {sim }}, E P_{\text {sim }}$ and observations, respectively, have a Rossby number larger than 0.1 (Fig. A1, right). That is, none of the detected eddies, in the models or observations, are in submesoscale range (here we follow $[56,76]$ who define submesoscale as features with a Rossby number of order 1, among other criteria; this contrasts with other works which define submesoscales as smaller than $50 \mathrm{~km}[72]$ ). Finally, as shown in Fig. A1 (left, note the logarithmic scale), most eddies have a non-linearity parameter $r$ larger than 1 .

\subsection{Eddy Genesis and Lifetime}

We start by comparing the rate and location of eddy genesis. Here, "eddy genesis" effectively refers the first time an eddy is identified. Although this is not the exact time when an eddy is born, this is a reasonable proxy. Fig. 1 shows maps of eddy genesis as the averaged frequency of first eddy detection in each $1^{\circ}$ grid box per year. 
Note that eddies require a minimum lifetime of 1 week to be identified by the detection algorithm. Differences between models and observations are not sensitive to this choice - see the eddy genesis maps for eddies lasting longer than 1 month in Fig. A2.

As expected eddies are not born homogeneously across the global ocean. Large genesis rates are found in the vicinity of intense currents such as the Antarctic Circumpolar Current (ACC) and boundary currents. Genesis rates are low in the open oceans, typically a factor of 4 smaller than in energetic regions. Model and observations share broadly similar distributions of eddy genesis although the modelled rates are significantly lower, notably in $E P_{\text {sim }}$. As a result, genesis rates in the gyre interiors of $E P_{\text {sim }}$ approach zero. In addition closer inspection reveals that genesis rates in $E P_{\text {sim }}$ at Eastern Boundary Currents (EBCs) are very weak compared to observations and $E R_{\text {sim }}$. This is particularly noticeable along the west coasts of Australia, Africa and South America around $20-30^{\circ} \mathrm{S}$. In contrast, $E R_{\text {sim }}$ is able to capture these hot-spots of eddy genesis, as well as generate as many eddies in the Southern Ocean as found in observations. This can be attributed to improvements in the representation of ocean currents and outflows in $E R_{\text {sim }}$, partly through improved topography, which provides a source of frontal shear for eddies to form [20]. For example improvements in $E R_{\text {sim }}$ are found in the Mediterranean outflow, EBCs, the ACC and the Drake passage, as well as in the East Australian and Leeuwin currents around Australia [41]. However, $E R_{\text {sim }}$ fails to capture the high genesis rates of the North Atlantic and North Pacific sub-polar gyres as well as the long-lived ( $>6$ months) cyclonic eddies from the Leeuwin Current and Tasman Outflow around Australia found in observations (see Fig. 2 below).

Table 1 shows the total number of eddies detected that last more than one week, as a crude measure of the global eddy genesis. In all data sets the genesis rate are similar for cyclonic and anti-cyclonic eddies. However consistent with Fig. 1, genesis rates are significantly lower in the models than in observations: $E R_{s i m}$ and $E P_{\text {sim }}$ generate only about $63 \%$ and $40 \%$ respectively of eddies found in observations. These biases in genesis rate are reflected in the eddy counts for eddies with lifetimes longer than 4 weeks (even for eddies living more than 16 weeks in $\left.E P_{\text {sim }}\right)$. For longer time-scales, other effects are playing a role (see below). These differences in eddy genesis between the $E R_{\text {sim }}$ and observations indicate that the $E R$ resolution may still be too coarse to generate mesoscale (coherent) eddies realistically. This may reflect that $1 / 12^{\circ}$ (and $1 / 4^{\circ}$ ) resolution fails to capture some smaller scale processes (e.g submesoscale activity, convection) that act as 'seeding' mechanisms for the mesoscale activity through an inverse cascade of energy $[65,10,56,9]$.

Consistent with the genesis rates, the density of eddy tracks is larger in $E R_{\text {sim }}$ and observations than in $E P_{\text {sim }}$ especially in eddy-energetic regions such as the Southern Ocean and WBCs (Fig. 2). For readability only eddy trajectories lasting longer than 6 months are shown (the trajectories for all eddies lasting more than 2 months cover most of the ocean as shown in Fig. A3).

Eddies lasting longer than 6 months are concentrated in the subtropical gyres between $20^{\circ}$ and $50^{\circ}$ latitude. They originate mainly from EBCs and to some extent from WBCs, notably from the Gulf Stream and North Atlantic drift. Overall, the $E P_{\text {sim }}$ significantly under-estimates the number of long lasting eddies although anti-cyclonic eddies from the Agulhas current retroflection ('Agulhas rings') are relatively well represented. 
These trajectories form an important component of the meridional overturning circulation by controlling the quantity of heat and salt entering the North Atlantic [7]. However in other locations an artificially high number of eddy trajectories is found in the $E P_{\text {sim }}$, for example west of the Indonesian outflow (which may affect the Agulhas leakage [5]). A striking feature of observations is the absence of long lived eddies within and south of the ACC path (note that eddies are detected as far as $70^{\circ} \mathrm{S}$, see Fig. A3). In contrast, in $E P_{\text {sim }}$ and most notably in $E R_{\text {sim }}$, the ACC path is highlighted by the presence of numerous long-lived eddies.

These differences between the $E R_{\text {sim }}, E P_{\text {sim }}$ and observations are reflected in the statistics of eddy lifetime (Fig. 3). On average eddies in $E P_{\text {sim }}$ and observations have shorter lifetimes than in $E R_{\text {sim }}$. The (normalized) probability density distributions of the eddy lifetimes are similar for $E P_{s i m}$ and observations but exhibit lower values than for $E R_{s i m}$ for lifetimes of 6 months and longer (Fig. 3, left).

Geographically, models and observations exhibit similar distributions of eddy lifetimes although, as expected from Fig. 2 and 3, values in $E R_{\text {sim }}$ are larger, with a global mean lifetime of 2 months compared to 1.8 months in $E P_{\text {sim }}$ and observations (Fig. 4). Eddy lifetimes are large in mid-latitudes (20-50 ) in all data sets, and large along the ACC pathway, notably in the Pacific sector in models. As highlighted by the zonal average (Fig. 3b), eddy lifetimes reach typically 2.2-2.4 months near 30-40 ${ }^{\circ} \mathrm{S}$ and fall to about 1.4-1.6 months at high latitudes and in the tropics. While models and observations show remarkable agreement in the Northern Hemisphere (Fig. 3b and Fig. 4), lifetimes in the models are consistently longer than in observations south of $\sim$ $40^{\circ} \mathrm{S}$. Near $60^{\circ} \mathrm{S}$, zonally averaged eddy lifetimes in $E P_{\text {sim }}$ and $E R_{\text {sim }}$ are (respectively) $\sim 1.2$ and $\sim 1.4$ times longer than in observations. At the highest latitudes, the presence of sea ice may partly explain the discrepancy as AVISO does not provide SSH data under sea while the models do [39]. However, the contrast between modelled and observed lifetimes is also clear in the core of the ACC which is ice-free all year long, suggesting other issues (see discussion below).

It is remarkable that, globally, the $E R_{\text {sim }}$ simulates as many eddies with lifetimes $>16$ weeks as seen in observations (Table 1) despite a significantly lower genesis rate (by 37\%). This implies that the "survival rate" of eddies is much larger in $E R_{\text {sim }}$ than in observations (and $E P_{\text {sim }}$ ) (Table 1). The survival rate up to 4 weeks is quite similar across the three data sets. However it is 1.5 times larger in $E R_{\text {sim }}$ than in observations at 16 weeks and up to 3 times larger at 1 year. It is noteworthy that the survival rates of observations and $E P_{\text {sim }}$ are very similar.

\subsection{Propagation}

Away from boundary currents and topography, eddies travel mainly in the zonal direction (Fig. 2). Theoretical predictions suggest that non-linear mesoscale eddies propagate westward with a velocity close to that of nondispersive long baroclinic Rossby waves [19]. The theoretical Rossby wave phase speed in the long wave limit is given by $C_{g}^{t}=-\beta R_{d}^{2}$ where $R_{d}$ is the Rossby radius of deformation. In the models, $R_{d}$ is computed as $R_{d}=\int_{-H}^{0} \frac{N}{|f| \pi} d z$ where $N(z)=\sqrt{-\frac{g}{\rho_{o}} \frac{d \rho}{d z}}$ (Brunt-Vaisala frequency) and $f$ is the Coriolis parameter. For observations, we use the Rossby radius from Chelton et al. [11]. As found in previous studies [e.g. 12, 46], the 
observed propagation speed of eddies, $C_{g}^{e d d y}$, closely matches the Rossby wave speed, $C_{g}^{t}$, outside of the ACC (Fig. 5). Note that Fig. 5 shows $C_{g}^{t}$ computed for the observed and modelled climatologies. At high-latitudes, the eddy propagation speed, $C_{g}^{e d d y}$, approaches zero but increases towards the equator up to $\sim 10-12 \mathrm{~cm} \mathrm{~s}^{-1}$ (westward). In the Southern Ocean however, eddies are carried eastward by the barotropic component of the ACC, resulting in a net eastward propagation speed of $\sim 1 \mathrm{~cm} \mathrm{~s}^{-1}$ [46]. Modelled zonal eddy propagation speed, $C_{g}^{e d d y}$, in both $E R_{\text {sim }}$ and $E P_{\text {sim }}$ shows very good agreement with observations, including in the ACC (Fig. 5). This reflects the good climatology of the models (also evidenced by the similarity of the modelled and observed Rossby radius, not shown) as well as a good representation of the barotropic ACC in both models.

The co-location of global westward-propagating eddy trajectories longer than 6 months reveals the small equatorward drift of anticyclonic and poleward drift of cyclonic eddies (Fig. 6). Figure 6 flips the direction of propagation for $\mathrm{NH}$ and $\mathrm{SH}$ eddies so the positive latitudes are equatorward and the negative latitudes are poleward. For anti-cyclones (red), this meridional displacement increases from observations to $E P_{\text {sim }}$, and to $E R_{\text {sim }}$ : the regression coefficients are $0.19,0.23$ and $0.3^{\circ}{ }^{\circ}$ for observations, the $E P_{\text {sim }}$ and $E R_{\text {sim }}$ with $R^{2}$ values of $69 \%, 82 \%$ and $78 \%$ respectively. This means that anti-cyclonic eddies in the $E R_{\text {sim }}$ are displaced by about $15^{\circ}$ latitude for every $50^{\circ}$ longitude travelled, whilst they are only displaced $\sim 10^{\circ}$ latitude in observations. Most of these long-lasting anti-cyclonic trajectories form part of the Agulhas rings. Compared to observations, a larger north-westward displacement of the Agulhas rings is also present in the stand-alone ocean component (Parallel Ocean program) of the Community Earth System Model, but this bias is reduced in the coupled simulations $[55,68]$. This suggests that the representation of air-sea feedback over mesoscale eddies may influence their meridional migration. Although a similar number of eddies are plotted in Fig. 6, differences also partly reflect the longer eddy-lifetime found in the models (Fig. 2 and 3) with longer-lasting anti-cyclonic eddies found in the $E R_{\text {sim }}$ compared to observations (and $E P_{\text {sim }}$ ). In $E R_{\text {sim }}$ and $E P_{\text {sim }}$, the meridional drift is smaller for cyclones than anti-cyclones with regression coefficients of $0.16^{\circ} /{ }^{\circ}$ and $0.15^{\circ} /{ }^{\circ}$ respectively (Fig. 6). However in observations, the meridional displacement is larger in cyclones $\left(0.23{ }^{\circ}{ }^{\circ}\right.$ ) than anti-cyclones $\left(0.19^{\circ} /{ }^{\circ}\right)$, and the displacement for each polarity is more symmetric than in the models. Many of these observed cyclonic trajectories are found in the Indian Ocean. These trajectories are absent from the models and may explain the asymmetric behavior found.

A simple measure of how "stationary" eddy are is given by the ratio $D / \overline{L_{e f f}}$, where $D$ is the absolute net zonal distance of propagation of an eddy and $\overline{L_{e f f}}$ is its lifetime-averaged effective radius (Fig. 7). This ratio is simply a measure of the zonal displacement of eddies in units of "eddy radius". Maps of $D / \overline{L_{e f f}}$ (Fig. 7) reveal that on average eddies are relatively stationary, moving by 3 or 4 times their radius. This is in contrast with the impression given by Figs. 2 and 6, which only include eddies longer than 6 months. Fig. 7 reflects that overwhelmingly eddies are short-lived, with life-times of about 2 months (see Fig. 3). $D / \overline{L_{e f f}}$ varies mainly in the meridional direction, decreasing from 6-7 in the Tropics down to 1-2 at high latitudes, which primarily reflect variations of the propagation speed $C_{g}^{e d d y}$. The 10 fold change in propagation speed between tropics and high-latitudes (Fig. 5) is somewhat reduced in $D / \overline{L_{e f f}}$ due to the counter acting effect of changes in $L_{e f f}$ 
(decreasing from the tropics to high latitudes, see below). Interestingly, the pattern of $D / \overline{L_{e f f}}$ in $E R_{s i m}$ is less zonally symmetric than in $E P_{\text {sim }}$ or observations, with enhanced values of $D / \overline{L_{e f f}}$ in eddy-energetic regions such as the Agulhas Current Retroflection, WBCs and along the ACC path. The latter feature notably is absent from observations, and reflects the smaller eddies detected in the ACC of $E R_{\text {sim }}$, which are not found in observations (see below). In the $E P_{\text {sim }}$, eddies are effectively more stationary than in $E R_{\text {sim }}$ or observations almost everywhere. This bias may affect the ability of eddies at this resolution to transport and mix properties in the zonal direction.

\subsection{Eddy Amplitude, Rotational Velocity and Radius}

Distributions of eddy amplitude and rotational velocity are very similar between the three datasets although there is a hint that the distribution of amplitudes in $E R_{\text {sim }}$ is narrower than in $E P_{\text {sim }}$ and observations (Fig. 8a). Most eddies have amplitudes $A$ between 1 and $5 \mathrm{~cm}$ with a median values of $2 \mathrm{~cm}$.

Differences in rotational velocity $U$ are more noticeable, although models and observations share similar distributions (Fig. 8b). The peak of the distribution is displaced toward larger values in $E R_{\text {sim }}\left(6 \mathrm{~cm} \mathrm{~s}^{-1}\right)$ compared with observations and $E P_{\text {sim }}\left(4 \mathrm{~cm} \mathrm{~s}^{-1}\right)$. In the $E R_{\text {sim }}, 19 \%$ of eddies have a velocity faster than $14 \mathrm{~cm} \mathrm{~s}^{-1}$ (dotted line in Fig.. 8b), whilst $14 \%$ do in the $E P_{\text {sim }}$ and $13 \%$ in observations. In addition the fastest eddies in the $E P_{\text {sim }}$, at about $80 \mathrm{~cm} \mathrm{~s}^{-1}$, are noticeably weaker than in the $E R_{\text {sim }}$ and observations at $120-140 \mathrm{~cm} \mathrm{~s}^{-1}$ (not shown).

The largest differences between the models and observations can be found when inspecting the radius of eddies (Fig. 9). Distributions are shown for both the speed-based $L_{s p d}$ and effective radii $L_{e f f}$. The three distributions of eddy radius $L_{s p d}$ are very distinct, with median values of 48,32 and $14 \mathrm{~km}$ for observations, $E P_{s i m}$ and $E R_{\text {sim }}$ respectively. In the $E R_{\text {sim }}$, about a quarter (24\%) of eddies have a radius $L_{s p d}$ equal to or smaller than $10 \mathrm{~km}$ while $90 \%$ of eddies have a radius $L_{s p d}$ equal to or smaller than $24 \mathrm{~km}$ (note that because of the convergence of the grid towards the poles, grid points can be significantly smaller than $10 \mathrm{~km}$ in $E R_{\text {sim }}$; see Fig. 10). Instead $23 \%$ of eddies in the $E P_{\text {sim }}$ and no eddies in observations have a radius $L_{s p d}$ equal to or smaller than $24 \mathrm{~km}$. Conversely, both the $E R_{\text {sim }}$ and $E P_{\text {sim }}$ do not capture many eddies with a large $L_{\text {spd }}$ : while in observations about $50 \%$ of eddies have a radius $L_{s p d}$ equal to or larger than $48 \mathrm{~km}$, only about $6 \%$ in the $E P_{\text {sim }}$ and $0.5 \%$ in the $E R_{\text {sim }}$ reach such values.

Differences are less striking, but still significant, in terms of the effective radius $L_{\text {eff }}$ (Fig. 9). $E P_{\text {sim }}$ and $E R_{\text {sim }}$ share similar distributions with median values of $52 \mathrm{~km}$ and $39 \mathrm{~km}$, respectively. The observed distribution for $L_{e f f}$ is centred around $50 \mathrm{~km}$ but it is narrower than in $E P_{\text {sim }}$. It is interesting to observe that $L_{e f f}$ and $L_{s p d}$ are more similar in observations than in the models (Fig. 9). While $L_{s p d}$ is only slightly smaller than $L_{e f f}$ in observations (as in [14]), it is typically 2-2.5 times smaller than $L_{e f f}$ in the models. $L_{s p d}$ is likely to be much smaller than $L_{e f f}$ for a Gaussian-shaped eddy whereas the two measures should be nearly equal for a quadratic-shaped eddy [e.g. 14]. This may suggest that the profiles of observed eddies are closer to a quadratic shape while the profiles of modelled eddies better match a Gaussian shape. More likely, this 
may reflect the large eddy radii found in observations. As the spatial scale grows in observations, closed SSH contours that satisfy the eddy algorithm criteria (e.g. no secondary extrema, shape test for circularity) are less likely to be found: $L_{s p d}$ is matched with $L_{e f f}$ (i.e. $L_{s p d}$ is reached at the edge of eddy).

\subsection{Controls on Eddy Scales}

Numerous studies have discussed processes that control the scale of ocean mesoscale eddies (e.g., $[22,78,75$, $69,47])$. In this section, we discuss the eddy scales of coherent vortices in observations (based on an updated dataset compared to previous publications) and the $E P_{\text {sim }}$ and $E R_{\text {sim }}$ simulations in the light of these previous studies. The relationship between the size of eddies, the Rossby radius of deformation and the Rhines scale $\left(L_{\text {Rhines }}=\sqrt{\frac{U_{r m s}}{2 \beta}}\right)$ is a recurring topic of investigation. A series of studies [75, 22, 79] have notably proposed that two regimes of ocean dynamics can be distinguished. They suggest that at low latitudes where $L_{\text {Rhines }}$ is smaller than $R_{d}$, eddies scales with $L_{\text {Rhines }}$ while at higher latitudes where $L_{\text {Rhines }}$ is larger than $R_{d}$, eddies scales with $R_{d}$. The transition between the two regimes is found near $30^{\circ} \mathrm{N} / \mathrm{S}$ (or $L_{\text {Rhines }} \simeq R_{d} \simeq 30 \mathrm{~km}$ ) equatorward of which baroclinic eddies can transfer their energy to Rossby waves [22, 79].

Starting with the models, it is interesting to note that the $E P$ resolution allows eddy growth and propagation in high latitudes, as far as $60-70^{\circ} \mathrm{N} / \mathrm{S}$, where the $E P$ grid scale is larger than the Rossby radius $R_{d}$. Following [37], Fig. 10 (top left) compares $R_{d}$ with twice the grid scale $\Delta x$ for the $E P$ and $E R$ resolutions. This criteria is inspired by linear stability analysis of baroclinic systems (e.g. the Eady and Charney problems; see [81] for a summary), which shows that maximum growth of linear waves is reached for wavelengths close to the Rossby radius of deformation. According to this simple criteria, eddies are expected to be found at nearly all latitudes in $E R_{\text {sim }}$ but should be absent poleward of $30^{\circ} \mathrm{N} / \mathrm{S}$ in $E P_{\text {sim }}$ [38]. As evidenced by Figs. 1 and 2, this simple criteria does not apply in $E P_{\text {sim }}$. It is worth recollecting that although linear stability analysis predicts a maximum growth around the Rossby radius scale, it also predicts instability for a range of wavelength, including those larger than $R_{d}$. For example in the Eady problem, all wavelengths larger than $2.6 R_{d}$ are unstable while in Philip's two-layer model, which includes a large wavelength cut-off due to the $\beta$-effect, unstable wavelengths are found between $2.2 R_{d}$ and $2 \pi \sqrt{U_{s} / \beta}$ (where $U_{s}$ is the mean vertical shear). We speculate that in regions where the grid scale is larger than the Rossby radius, instability and eddy growth remain possible but occur on scales significantly larger than the Rossby radius (or than the scale of the maximum theoretical growth rate). Indeed, most eddies in $E P_{\text {sim }}(81 \%)$ are larger than $R_{d}$, unlike in $E R_{\text {sim }}$ where only $20 \%$ are. This suggests that in the models (notably in $E R_{\text {sim }}$ ) the eddy scale is partly set by the grid scale or the smallest multiple of $\Delta x$ that allows the development of instabilities. It should also be noted that C-grids (as used in NEMO) may develop a spurious baroclinic short-wave instability [4]. Such spurious mode may contribute to the smaller eddy scales found in $E R_{\text {sim }}$.

Further comparison reveals that the nominal and effective resolutions of these datasets, to be contrasted with the resolution of the underlying physics, also have a major influence on the estimated scales. To highlight this, the distribution of eddy scales for the $E R$ resolution outputs are re-gridded to EP resolution (referred to as 
$E R_{\text {sim }}$ regrid) as shown in Fig. 9 (dotted lines). Through the remapping, the peak of the distributions for $L_{s p d}$ in $E R_{\text {sim }}$ increases from $12 \mathrm{~km}$ to $28 \mathrm{~km}$. For $L_{e f f}$, after remapping the distribution of $E R_{\text {sim }}$ is shifted to larger values by $12 \mathrm{~km}$. Sensitivity tests with the high-pass filtering of the SSH field does not alter significantly the eddy radius distributions (not shown). Not surprisingly, estimates of eddy scales are highly sensitive to the resolution of the dataset. It is however striking that the distributions of eddy radii for $E R_{\text {sim }}$ regrid are nearly identical to those for $E P_{\text {sim }}$. This reinforces the argument above that eddies grow on a scale set by the grid scale. Despite having the same nominal grid resolution of $1 / 4^{\circ}$, observed eddy radii exhibit marked differences with those of $E P_{\text {sim }}$ and $E R_{\text {sim }}$ regrid, notably for $L_{\text {spd }}$. If the re-mapping of $E R_{\text {sim }}$ to $E R_{\text {sim }}$ regrid is any guidance, this suggests that the effective resolution of the gridded observational dataset is larger than $1 / 4^{\circ}$ and possibly closer to $1 / 2^{\circ}$.

A comparison of $R_{d}, L_{\text {Rhines }}$ and $L_{s p d}$ is shown in Figs. 10 and 11. Equivalent plots for $L_{e f f}$, which is more noisy than $L_{s p d}$, are shown in Fig. A4 and A5. Here we use $U_{r m s}=\sqrt{E K E_{g}}$ to compute $L_{R h i n e s}$ where $E K E_{g}$ is the surface geostrophic eddy kinetic energy (computed from 10 years of daily SSH anomalies for the $E P_{\text {sim }}$ and observations and from 5 years for the $\left.E R_{\text {sim }}\right)$. Note that $L_{\text {Rhines }}$ is not defined in a standard way in the literature. [22] uses the EKE associated with the barotropic flow. However, as the eddy velocity is surface-intensified, our calculation of the Rhines scale is very similar to that of [22] (his Fig. 6). [79] define $L_{\text {Rhines }}$ as $2 \pi \sqrt{\frac{2 U_{r m s}}{\beta}}$ and estimate $U_{r m s}$ as the root mean square of the eddy velocity from surface drifter data. Since their $U_{r m s}$ and ours are similar (at least outside of the equatorial band, not shown), their estimate of the Rhines scale for observations differs from ours (Fig. 10, top right) by a factor $4 \pi$. The Rhines scale is similar for models and observations, ranging between approximately 30 and $60 \mathrm{~km}$ (Fig. 10) ${ }^{1}$. Compared to the Rossby radius $R_{d}, L_{\text {Rhines }}$ exhibit a relatively flat, although noisy, meridional profile in all three datasets. As the Rossby radius is also similar in models and observations, the ocean is separated in two regimes, with $R_{d} \leq L_{\text {Rhines }}$ poleward of $30^{\circ} \mathrm{N} / \mathrm{S}$ and $L_{\text {Rhines }} \leq R_{d}$ equatorward of $30^{\circ} \mathrm{N} / \mathrm{S}$.

The eddy radii vary quasi-linearly with latitude, increasing toward the equator (Fig. 10). Consistent with Fig. 9, the zonally-averaged eddy radii are smallest in $E R_{\text {sim }}$ and largest in observations. Again, eddy radii in the regridded $E R_{\text {sim }}$ is very similar to $E P_{\text {sim }}$ (dark green line in Fig. 10). Note that the observed radii $L_{\text {eff }}$ (Fig. A4) compare well with Fig. 11 in [79] although our eddy radii are smaller. As the eddy detection algorithm used in this study is essentially based on [15], this difference may be attributed to the fact that we use a more recent altimeter product (with finer resolution).

Scatter plots of $L_{s p d}$ versus $R_{d}$ or the minimum of $R_{d}$ and $L_{R h i n e s}$ are shown in Fig. 11 (see Fig. A5 for $L_{e f f}$ ). For observations and models, a good linear fit is found between $L_{s p d}$ (or $L_{e f f}$ ) and $R_{d}$, although the slope of the best fit between $L_{s p d}$ and $R_{d}$ is slightly weaker in the $E R_{\text {sim }}$ than in observations and the $E P_{\text {sim }}$ : for the $E R_{\text {sim }}, E P_{\text {sim }}$ and observations slopes are $0.22,0.35$ and 0.35 with $R^{2}$ values of $90 \%, 80 \%$ and $82 \%$

\footnotetext{
${ }^{1}$ Note that there is no contradiction with the fact that $L_{s p d}$ differs substantially between models and observations as the Rhines scale and $L_{s p d}$ are not directly related. $L_{\text {Rhines }}$ depends on the square root of the total geostrophic eddy kinetic energy while $L_{s p d}$ measures the distance between the eddy centre and the closed SSH contour with maximum averaged geostrophic velocity within an eddy.
} 
respectively (Fig. 11, left column). For observations, this slope (0.35) is significantly smaller than the value of 0.8 found in [22] in the North Atlantic while the fit found here appears much better than that seen in [22]. For both $L_{s p d}$ and $L_{e f f}$, the relationship with $R_{d}$ appears to break down (more scatter) for $R_{d}$ larger than $\sim 100 \mathrm{~km}$ (not shown). The scatter plots shown here are taken globally but a similar relationship is found for the North Atlantic only (see Fig. A6). Note however that [22] uses a different measure of the eddy size (based on the first zero-crossing of the spatial auto-correlation function of SSH anomalies) as well a older version of the SSH altimeter product.

Following [22], we test the relationship between the eddy radii and the minimum of $R_{d}$ and $L_{R h i n e s}$ (Fig. 11, A5 and A6, right column). The shade of colour indicates whether the minimum is reached with $R_{d}$ (darker shade) or $L_{\text {Rhines }}$ (lighter shade). In observations and $E P_{\text {sim }}$, the link between eddy radii and $\min \left(R_{d}, L_{\text {Rhines }}\right)$ appears better than between eddy radii and $R_{d}$ alone, as suggested in previous studies [e.g. $22,78]$. Replacing $R_{d}$ by $\min \left(R_{d}, L_{R h i n e s}\right)$ clearly results in a more linear relationship to $L_{\text {spd }}$, as highlighted by the increased $R^{2}$ value, except from in $E R_{\text {sim }}$. However, this needs to be contrasted with the fact that the improvement of the fit (as measured by $R^{2}$ ) is often marginal and is sensitive to the choice of domain and of eddy radius definition (as shown for $L_{e f f}$ and for the North Atlantic in Figs. A5 and A6). Note that, as in [22], the slopes in $E P_{\text {sim }}$ and observations are roughly double for $\min \left(R_{d}, L_{R h i n e s}\right)$ relative to $R_{d}$.

\section{Conclusions}

Strengths and limitations of ocean simulations at $E R$ and $E P$ resolution in the representation of mesoscale eddies are explored. We focus on the surface properties of eddies using an eddy tracking algorithm on SSH anomalies. Modelled properties are compared to observed properties evaluated from the satellite altimeter AVISO product. An ocean model's ability to better-represent eddies in eddy-energetic regions, such as the WBCs, the Agulhas retroflection and the Southern Ocean, has important implications for heat transport, global ocean stratification and eddy energy dissipation $[58,51,88]$.

The key findings are summarized below:

- Amplitude, rotational speed and propagation speed of eddies are very similar across observations and models.

- $E R$ and EP resolutions generate only $\sim 63 \%$ and $40 \%$ respectively as many eddies as in observations. A leading factor for this discrepancy is the low count (or sometimes complete absence in $E P$ ) of eddy generation in the mid-ocean gyres and in Eastern Boundary Currents.

- Eddy lifetime are biased low in the $E P_{\text {sim }}$ compared to observations but biased high in the $E R_{\text {sim }}$, notably in the Southern ocean where the averaged eddy lifetime is about $30 \%$ larger than observed.

- Compared to $E P_{\text {sim }}$ and observations, eddies are significantly smaller in $E R_{\text {sim }}$. This is true for both measures of eddy radius (speed-based and effective radius) although the differences are more striking for 
the speed-based radius.

- Eddy radii scale closely with the Rossby radius of deformation, $R_{d}$, in all three datasets. As suggested in previous studies, eddy sizes also relate well to the minimum of the $R_{d}$ and the Rhines scale $L_{\text {Rhines }}$. The improvement in the fit from $R_{d}$ alone to $\min \left(R_{d}, L_{R h i n e s}\right)$ is particularly notable in the $E R_{\text {sim }}$ and $E P_{\text {sim }}$

- In contrast with suggestions from previous studies, $E P_{\text {sim }}$ simulates a significant population of eddies up to the high latitudes where the model grid-scale is larger than the Rossby radius of deformation, $R_{d}$. These eddies likely grow on scales set by the smallest combination of grid-points that allows instability.

For the number of metrics explored in this study, it is difficult to objectively evaluate whether $E R$ resolution provides a significant improvement over $E P$ resolution, in part due to concerns with the fact that observations can provide a robust benchmark. Instead advantages of the $E R_{\text {sim }}$, compared to $E P_{\text {sim }}$, depend on the properties and region of interest. Benefits of the $E R_{\text {sim }}$ include a similar number of eddies in the Southern Ocean, and globally a similar number of eddies living longer than 16 weeks, compared to observations. $E R_{\text {sim }}$ eddies are less stationary and smaller eddies are able to develop, compared to the $E P_{\text {sim }}$. The genesis rate and size of the eddy populations are clear examples where the $E R_{\text {sim }}$ improves upon $E P_{\text {sim }}$. This is likely the result of a better representation of the mean state in the $E R_{\text {sim }}$ in eddy-energetic regions such as boundary currents and the ACC. Eddies generated in Eastern Boundary Currents are important for transferring heat and nutrients into the nutrient-poor open ocean $[28,31]$. In that regard, the $E R_{\text {sim }}$ clearly outperform the EPsim where the basin interior are relatively empty of eddies.

In other aspects, outcomes of the model-observation comparison are more ambiguous. Our results suggest that the $E R_{\text {sim }}$ over-estimates the survival rate of eddies. The dissipation of mesoscale eddies in the ocean remains an open question with a number of competing ideas being explored e.g. enhanced friction over rough bottom topography, the emission of internal waves, coupling to the atmosphere, the role of symmetric instability in the open ocean or interaction with WBCs $[88,18,35,87]$. It is not expected that such processes are captured in $E R$ (nor $E P$ ) resolution models. Our analysis suggests that as resolution increases, allowing more vigorous eddies and a lower viscosity (for numerical stability), the absence of dissipation mechanisms may become problematic and introduce biases in the lifetime of the modelled eddies. However, we cannot rule out that eddy lifetime estimates are biased low in observations due to post-processing and smoothing of the SSH data that would limit the ability to track eddies.

The differences in eddy size are a particularly striking outcome of our analysis. Our results suggest that the eddy size is overestimated in observations by a factor 2 and possibly up to 4 depending on the considered measure. The nominal resolution of the dataset is a key factor here and, consistent with previous studies, our analysis suggests that the effective resolution of the AVISO gridded dataset is coarser than $1 / 4^{\circ}[13,14,73,3]$. Instead, the effective resolution in the $E R_{\text {sim }}$ is much higher than in observations but the subsequent impact of the smaller eddies found in the $E R_{\text {sim }}$ is unclear. Whether the total energy or heat contained within a greater 
number of smaller eddies in the $E R_{\text {sim }}$ is similar to the fewer, larger eddies found in the $E P_{\text {sim }}$ remains to be determined. Further studies are needed to explore the role of the tracked eddies in air-sea and surface-subsurface coupling within the climate system. An overestimation of eddy scales in observations could have implications for eddy parameterization and interpretation of ocean dynamics. Mixing length arguments underlying many eddy parameterizations use the eddy scale as proxy for the mixing length [45]. Direct comparison of properties (e.g. wavenumber spectrum, see [66]) along satellite tracks should help clarify to which extent differences between model and observations are robust or due to the post-processing necessary to generate the AVISO gridded product.

Finally, it must be noted that our model represents one set of parameter choices, for example the sensitivity to viscosity has not been tested, and only surface eddy properties are evaluated. Further studies should explore the 3-dimensional structure of eddies, the influence of eddies of air-sea exchanges and energy spectra to compare the redistribution of kinetic energy at larger scales for each resolution [43]. Limitations of the eddy tracking algorithm should not be underestimated [14]. It is likely that some of our results (e.g. eddy counts) are dependent on our choice of eddy detection algorithm. However we have attempted to minimize its impact by applying the same algorithm to models and observations and focus our analysis on differences/similarities rather than the absolute values. This work lays the foundation for future studies at different resolutions and using different models as more high resolution data become available in which submesoscales start to be resolved. Observational SSH global datasets are likely to improve as satellite altimetry coverage is enhanced with the future launch of the SWOT altimeter.

Acknowledgements: This work is funded by SCENARIO DTP and the Met Office CASE studentship. Met Office authors were supported by the Joint UK BEIS/Defra Met Office Hadley Centre Climate Programme (GA01101). M. Roberts acknowledges funding received from the European Commission under Grant Agreement 641727 (PRIMAVERA project) of the Horizon 2020 research programme. 


\section{Appendix}

\subsection{Algorithm details}

Further discussion of the eddy identification and tracking scheme, criteria and adaptations are listed below. SSH contours are computed from $100 \mathrm{~cm}$ to $-100 \mathrm{~cm}$ with an interval of $0.3 \mathrm{~cm}$. Starting from a SSH minimum (cyclone) or maximum (anti-cyclone), the algorithm identifies successive closed contours. There is no set minimum or maximum eddy radius; instead an eddy's size is limited by its pixel range. In order for an eddy to be successfully identified each closed contour of SSH needs to lie within a specific pixel range between 8 and 10,000. Therefore when increasing the grid resolution the same minimum pixel number of 8 allow smaller eddies to be detected compared to a coarser resolution.

Adaptations from the original eddy tracking algorithm [54] include:

- The identification and tracking components of the algorithm were split so global identification at each daily timestep is run in parallel to increase computational efficiency. For a chosen region and time period, eddies are then able to be tracked from the already identified eddy centres. All eddy tracks (and their associated properties such as radius, rotational velocity and amplitude) are stored and for eddies left 'active' (not masked), their tracks are able to be resumed for future tracking.

- The regular grid is adapted for use with the irregular NEMO ocean grid. A remaining limitation to our method is the ability to wrap tracks across the irregular NEMO grid divide at approximately $73^{\circ} \mathrm{E}$. This slight jump in tracks is assumed to not have a large consequence on global statistics and there is no obvious increase in eddy birth and death frequency either side of this divide. This can be observed in Figs. 1 and 7.

- Improvements were made in the unrealistic 'jumping' of eddy tracks by changing the search ellipse used to find the following identified eddy contour in its track. This was based on tracking improvements published online associated with a collaboration with AVISO [A. Delepoulle et al. OSTST 2017, Mesoscale Eddies in Altimeter Observations of SSH web site at OSU, http : //wombat.coas.oregonstate.edu/eddies/, accessed 08.11.18.]

A link to the AVISO handbook can be found here with details of the tracking method: https ://www.aviso. altimetry.fr/fileadmin/documents/data/tools/hdbk eddytrajectory 2.0exp.pdf accessed 20.03.19 


\section{References}

[1] R. Abernathey and G. Haller. Transport by Lagrangian Vortices in the Eastern Pacific. Journal of Physical Oceanography, 48:667-685, 2018.

[2] R. Abernathey, J. Marshall, and D. Ferreira. The Dependence of Southern Ocean Meridional Overturning on Wind Stress. Journal of Physical Oceanography, 41(12):2261-2278, 2011.

[3] B. K. Arbic, K. L. Polzin, J. F. Shriver, R. B. Scott, and J. G. Richman. On Eddy Viscosity, Energy Cascades, and the Horizontal Resolution of Gridded Satellite Altimeter Products*. Journal of Physical Oceanography, 43(2):283-300, 2013.

[4] W. Barham, S. Bachman, and I. Grooms. Some effects of horizontal discretization on linear baroclinic and symmetric instabilities. Ocean Modelling, 125(March):106-116, 2018.

[5] D. L. Bars, H. A. Dijkstra, and W. P. M. D. Ruijter. Impact of the Indonesian Throughflow on the Atlantic Meridional Overturning Circulation. Ocean Science, 16(5):5470, 2014.

[6] M. Bates, R. Tulloch, J. Marshall, and R. Ferrari. Rationalizing the Spatial Distribution of Mesoscale Eddy Diffusivity in Terms of Mixing Length Theory. Journal of Physical Oceanography, 44(6):15231540, 2014.

[7] A. Biastoch, J. R. Lutjeharms, C. W. Böning, and M. Scheinert. Mesoscale perturbations control interocean exchange south of Africa. Geophysical Research Letters, 35(20):2000-2005, 2008.

[8] L. Brannigan. Intense submesoscale upwelling in anticyclonic eddies. Geophysical Research Letters, 43(7):3360-3369, 2016.

[9] L. Brannigan, D. P. Marshall, A. C. Naveira Garabato, A. George Nurser, and J. Kaiser. Submesoscale instabilities in mesoscale eddies. Journal of Physical Oceanography, pages JPO-D-16-0178.1, 2017.

[10] J. Callies and R. Ferrari. Baroclinic Instability in the Presence of Convection. Journal of Physical Oceanography, 48(1):45-60, 2017.

[11] D. B. Chelton, R. a. DeSzoeke, M. G. Schlax, K. El Naggar, and N. Siwertz. Geographical Variability of the First Baroclinic Rossby Radius of Deformation. Journal of Physical Oceanography, 28(3):433-460, 1998.

[12] D. B. Chelton and M. G. Schlax. Global Observations of Oceanic Rossby Waves. Science, 272(5259):234238, 1996.

[13] D. B. Chelton and M. G. Schlax. The accuracies of smoothed sea surface height fields constructed from tandem satellite altimeter datasets. Journal of Atmospheric and Oceanic Technology, 20(9):1276-1302, 2003. 
[14] D. B. Chelton, M. G. Schlax, and R. M. Samelson. Global observations of nonlinear mesoscale eddies. Progress in Oceanography, 91:167 - 216, 2011.

[15] D. B. Chelton, M. G. Schlax, R. M. Samelson, and R. A. de Szoeke. Global observations of large oceanic eddies. Geophysical Research Letters, 34(15):1-5, 2007.

[16] D. B. Chelton and S.-P. Xie. Coupled ocean-atmosphere interaction at oceanic mesoscales. Magazine of Oceanography, 23(4):52-69, 2010.

[17] P. Cipollini, D. Cromwell, M. S. Jones, G. D. Quartly, and P. G. Challenor. Concurrent altimeter and infrared observations of Rossby wave propagation near $34 \mathrm{~N}$ in the Northeast Atlantic. Geophysical Research Letters, 24(8):889-892, 1997.

[18] L. Clément, E. Frajka-Williams, K. L. Sheen, J. A. Brearley, and A. C. N. Garabato. Generation of Internal Waves by Eddies Impinging on the Western Boundary of the North Atlantic. Journal of Physical Oceanography, 46(4):1067-1079, 2016.

[19] B. Cushman-Roisin, E. Chassignet, and T. Benyang. Westward Motion of Mesoscale Eddies. Journal of Physical Oceanography, 20:758 - 767, 1990.

[20] B. Deremble, W. K. Dewar, and E. P. Chassignet. Vorticity Dynamics near sharp topographic features. Journal of Marine Research, 74:249-276, 2016.

[21] N. Ducet, P. Y. Le Traon, and G. Reverdin. Global high-resolution mapping of ocean circulation from TOPEX/Poseidon and ERS-1 and -2. Journal of Geophysical Research: Oceans, 105(C8):19477-19498, 2000.

[22] C. Eden. Eddy length scales in the North Atlantic Ocean. Journal of Geophysical Research, 112(C6):C06004, 2007.

[23] C. Eden and R. J. Greatbatch. Diapycnal mixing by meso-scale eddies. Ocean Modelling, 23(3-4):113$120,2008$.

[24] Esmf, B. Boville, S. Cheung, T. Clune, T. Craig, C. Cruz, A. Silva, C. Deluca, R. D. Fainchtein, B. Eaton, B. Hallberg, T. Henderson, C. Hill, M. Iredell, R. Jacob, P. Jones, E. Kluzek, B. Kauffman, J. Larson, P. Li, F. Liu, J. Michalakes, S. Murphy, D. Neckels, R. O. Kuinghttons, B. Oehmke, C. Panaccione, J. Rosinski, W. Sawyer, E. Schwab, S. Smithline, W. Spector, D. Stark, M. Suarez, S. Swift, A. Trayanov, S. Vasquez, J. Wolfe, W. Yang, and M. Young. Earth System Modeling Framework ESMF Reference Manual. 2014.

[25] V. Eyring, S. Bony, G. A. Meehl, C. A. Senior, B. Stevens, R. J. Stouffer, and K. E. Taylor. Overview of the Coupled Model Intercomparison Project Phase 6 (CMIP6) experimental design and organization. Geoscientific Model Development, 9(5):1937-1958, 2016. 
[26] F. Fang and R. Morrow. Evolution, movement and decay of warm-core Leeuwin Current eddies. Deep-Sea Research Part II: Topical Studies in Oceanography, 50(12-13):2245-2261, 2003.

[27] B. Fox-kemper and S. Bachman. Principles and advances in subgrid modelling for eddy-rich simulations. CLIVAR Exchanges: Special Issue: High Resolution Ocean Climate Modelling, 19(65), 2014.

[28] I. Frenger, D. Bianchi, C. Stührenberg, A. Oschlies, J. Dunne, C. Deutsch, E. Galbraith, and F. Schütte. Biogeochemical Role of Subsurface Coherent Eddies in the Ocean: Tracer Cannonballs, Hypoxic Storms, and Microbial Stewpots? Global Biogeochemical Cycles, 32:1 - 24, 2018.

[29] I. Frenger, N. Gruber, R. Knutti, and M. Münnich. Imprint of Southern Ocean eddies on winds, clouds and rainfall. Nature Geoscience Letters, 6:608 - 612, 2013.

[30] P. Gaube, C. Barceló, D. J. McGillicuddy, A. Domingo, P. Miller, B. Giffoni, N. Marcovaldi, and Y. Swimmer. The use of mesoscale eddies by juvenile loggerhead sea turtles (Caretta caretta) in the southwestern Atlantic. PLoS ONE, 12(3), 2017.

[31] P. Gaube, D. B. Chelton, R. M. Samelson, M. G. Schlax, and L. W. O 'neill. Satellite Observations of Mesoscale Eddy-Induced Ekman Pumping. Journal of Physical Oceanography, 45:104 - 132, 2014.

[32] P. R. Gent and J. C. Mcwilliams. Isopycnal Mixing in Ocean Circulation Models, 1990.

[33] A. L. Gordon and C. F. Giulivi. Ocean eddy freshwater flux convergence into the North Atlantic subtropics. Journal of Geophysical Research : Oceans, 119, 2014.

[34] S. M. Griffies, M. Winton, W. Anderson, R. Benson, T. L. Delworth, C. O. Dufour, J. P. Dunne, P. Goddard, A. K. Morrison, A. Rosati, A. T. Wittenberg, J. Yin, and R. Zhang. Impacts on ocean heat from transient mesoscale eddies in a hierarchy of climate models. Journal of Climate, 28(3):952-977, 2015.

[35] J. Gula, M. J. Molemaker, and J. C. McWilliams. Topographic generation of submesoscale centrifugal instability and energy dissipation. Nature Communications, 7:1-7, 2016.

[36] R. J. Haarsma, M. J. Roberts, P. L. Vidale, A. Catherine, A. Bellucci, Q. Bao, P. Chang, S. Corti, N. S. Fučkar, V. Guemas, J. Von Hardenberg, W. Hazeleger, C. Kodama, T. Koenigk, L. R. Leung, J. Lu, J. J. Luo, J. Mao, M. S. Mizielinski, R. Mizuta, P. Nobre, M. Satoh, E. Scoccimarro, T. Semmler, J. Small, and J. S. Von Storch. High Resolution Model Intercomparison Project (HighResMIP v1.0) for CMIP6. Geoscientific Model Development, 9(11):4185-4208, 2016.

[37] R. Hallberg. Using a resolution function to regulate parameterizations of oceanic mesoscale eddy effects. Ocean Modelling, 72:92-103, 2013.

[38] R. Hallberg and A. Gnanadesikan. The Role of Eddies in Determining the Structure and Response of the Wind-Driven Southern Hemisphere Overturning: Results from the Modeling Eddies in the Southern Ocean (MESO) Project. Journal of Physical Oceanography, 36(12):2232-2252, 2006. 
[39] H. Hewitt, M. J. Roberts, P. Hyder, T. Graham, J. Rae, S. E. Belcher, R. Bourdallé-Badie, D. Copsey, A. Coward, C. Guiavarch, C. Harris, R. Hill, J. J. Hirschi, G. Madec, M. S. Mizielinski, E. Neininger, A. L. New, J. C. Rioual, B. Sinha, D. Storkey, A. Shelly, L. Thorpe, and R. A. Wood. The impact of resolving the Rossby radius at mid-latitudes in the ocean: Results from a high-resolution version of the Met Office GC2 coupled model. Geoscientific Model Development, 9(10):3655-3670, 2016.

[40] H. T. Hewitt, M. J. Bell, E. P. Chassignet, A. Czaja, D. Ferreira, S. M. Griffies, P. Hyder, J. L. McClean, A. L. New, and M. J. Roberts. Will high-resolution global ocean models benefit coupled predictions on short-range to climate timescales?, 2017.

[41] J. Holt, P. Hyder, M. Ashworth, J. Harle, H. T. Hewitt, H. Liu, A. L. New, S. Pickles, A. Porter, E. Popova, J. Icarus Allen, J. Siddorn, and R. Wood. Prospects for improving the representation of coastal and shelf seas in global ocean models. Geoscientific Model Development, 10(1):499-523, 2017.

[42] P. W. Jones and T. Division. A User's Guide for SCRIP: A Spherical Coordinate Remapping and Interpolation Package. page 27, 1998.

[43] J. Kjellsson and L. Zanna. The impact of horizontal resolution on energy transfers in global ocean models. Fluids, 2(3), 2017.

[44] P. Klein, G. Lapeyre, L. Siegelman, B. Qiu, L. L. Fu, H. Torres, Z. Su, D. Menemenlis, and S. Le Gentil. Ocean-Scale Interactions From Space. Earth and Space Science, 6(5):795-817, 2019.

[45] A. Klocker and R. Abernathey. Global Patterns of Mesoscale Eddy Properties and Diffusivities. Journal of Physical Oceanography, 44(3):1030-1046, 2013.

[46] A. Klocker and D. P. Marshall. Advection of baroclinic eddies by depth-mean flow. Geophysical Research Letters, 41:3517 - 3521, 2014.

[47] A. Klocker, D. P. Marshall, S. R. Keating, and P. L. Read. A regime diagram for ocean geostrophic turbulence. Quarterly Journal of the Royal Meteorological Society, 142(699):2411-2417, 2016.

[48] J. Kurian, F. Colas, X. Capet, J. C. McWilliams, and D. B. Chelton. Eddy properties in the California Current System. Journal of Geophysical Research: Oceans, 116(8), 2011.

[49] Q. Y. Li, L. Sun, and S. F. Lin. GEM: A dynamic tracking model for mesoscale eddies in the ocean. Ocean Science, 12(6):1249-1267, 2016.

[50] G. Madec. NEMO ocean engine. Note du Pôle de modélisation, Institut Pierre-Simon Laplace (IPSL), France, (27):1 - 396, 2008.

[51] D. P. Marshall, M. H. Ambaum, J. R. Maddison, D. R. Munday, and L. Novak. Eddy saturation and frictional control of the Antarctic Circumpolar Current. Geophysical Research Letters, 44(1):286-292, 2017. 
[52] J. Marshall and T. Radko. Residual-Mean Solutions for the Antarctic Circumpolar Current and Its Associated Overturning Circulation. Journal of Physical Oceanography, 33(11):2341-2354, 2003.

[53] A. Marzocchi, J. J. Hirschi, N. P. Holliday, S. A. Cunningham, A. T. Blaker, and A. C. Coward. The North Atlantic subpolar circulation in an eddy-resolving global ocean model. Journal of Marine Systems, 142:126-143, 2015.

[54] E. Mason, A. Pascual, and J. C. McWilliams. A new sea surface height-based code for oceanic mesoscale eddy tracking. Journal of Atmospheric and Oceanic Technology, 31(5):1181-1188, 2014.

[55] J. L. McClean, D. C. Bader, F. O. Bryan, M. E. Maltrud, J. M. Dennis, A. A. Mirin, P. W. Jones, Y. Y. Kim, D. P. Ivanova, M. Vertenstein, J. S. Boyle, R. L. Jacob, N. Norton, A. Craig, and P. H. Worley. A prototype two-decade fully-coupled fine-resolution CCSM simulation. Ocean Modelling, 39(1-2):10-30, 2011.

[56] J. C. McWilliams. Submesoscale currents in the ocean. Proceedings in Royal Society, 472:1 - 32, 2016.

[57] S. Minobe, A. Kuwano-Yoshida, N. Komori, S.-P. Xie, and R. J. Small. Influence of the Gulf Stream on the troposphere. Nature: Letters, 452:206 - 209, 2008.

[58] D. R. Munday, H. L. Johnson, and D. P. Marshall. Eddy Saturation of Equilibrated Circumpolar Currents. Journal of Physical Oceanography, 43(3):507-532, 2013.

[59] V. Oerder, F. Colas, V. Echevin, S. Masson, and F. Lemarié. Impacts of the Mesoscale Ocean-Atmosphere Coupling on the Peru-Chile Ocean Dynamics: The Current-Induced Wind Stress Modulation. Journal of Geophysical Research: Oceans, 123:1-22, 2018.

[60] L. Renault, M. J. Molemaker, J. Gula, S. Masson, and J. C. McWilliams. Control and Stabilization of the Gulf Stream by Oceanic Current Interaction with the Atmosphere. Journal of Physical Oceanography, 46(11):3439-3453, 2016.

[61] L. Renault, M. J. Molemaker, J. C. McWilliams, A. F. Shchepetkin, F. Lemarié, D. B. Chelton, S. Illig, and A. Hall. Modulation of Wind-Work by Oceanic Current Interaction with the Atmosphere. Journal of Climate, 46:1685 - 1703, 2016.

[62] J. K. Ridley, E. W. Blockley, A. B. Keen, J. G. L. Rae, and A. E. West. The sea ice model component of HadGEM3-GC3 . 1. Geoscientific Model Development, 11:713 - 723, 2018.

[63] M. J. Roberts, A. Baker, E. W. Blockley, D. Calvert, A. Coward, H. T. Hewitt, L. C. Jackson, T. Kuhlbrodt, P. Mathiot, C. D. Roberts, R. Schiemann, J. Seddon, B. Vannière, and P. L. Vidale. Description of the resolution hierarchy of the global coupled HadGEM3-GC3.1 model as used in CMIP6 HighResMIP experiments. Geoscientific Model Development Discussions, in review(June):1-47, 2019. 
[64] M. J. Roberts, H. T. Hewitt, P. Hyder, D. Ferreira, S. A. Josey, M. Mizielinski, and A. Shelly. Impact of ocean resolution on coupled air-sea fluxes and large-scale climate. Geophysical Research Letters, 43(19):10,430-10,438, 2016.

[65] H. Sasaki, P. Klein, B. Qiu, and Y. Sasai. Impact of oceanic-scale interactions on the seasonal modulation of ocean dynamics by the atmosphere. Nature Communications, 5:1-8, 2014.

[66] M. G. Scharffenberg and D. Stammer. Statistical parameters of the geostrophic ocean flow field estimated from the Jason-1-TOPEX/Poseidon tandem mission. Journal of Geophysical Research: Oceans, 116(12):1-14, 2011.

[67] D. V. Sein, N. V. Koldunov, S. Danilov, Q. Wang, D. Sidorenko, I. Fast, T. Rackow, W. Cabos, and T. Jung. Ocean Modeling on a Mesh With Resolution Following the Local Rossby Radius. Journal of Advances in Modeling Earth Systems, 9(7):2601-2614, 2017.

[68] R. J. Small, J. Bacmeister, D. Bailey, A. Baker, S. Bishop, F. Bryan, J. Caron, J. Dennis, P. Gent, H.-m. Hsu, M. Jochum, D. Lawrence, E. Muñoz, P. DiNezio, T. Scheitlin, R. Tomas, J. Tribbia, Y.-h. Tseng, and M. Vertenstein. A new synoptic scale resolving global climate simulation using the Community Earth System Model. Journal of Advances in Modeling Earth Systems, 6(4):1065-1094, 2014.

[69] D. Stammer. Global Characteristics of Ocean Variability Estimated from Regional TOPEX POSEIDON Altimeter Measurements. Journal of Physical Oceanography, 27:1743-1769, 1997.

[70] D. Storkey, A. T. Blaker, P. Mathiot, A. Megann, Y. Aksenov, E. W. Blockley, D. Calvert, T. Graham, H. T. Hewitt, P. Hyder, T. Kuhlbrodt, J. G. L. Rae, and B. Sinha. UK Global Ocean GO6 and GO7: a traceable hierarchy of model resolutions. Geoscientific Model Development, 11(8):3187-3213, 2018.

[71] Z. Su and A. P. Ingersoll. On the minimum potential energy state and the eddy size-constrained ape density. Journal of Physical Oceanography, 46(9):2663-2674, 2016.

[72] Z. Su, J. Wang, P. Klein, A. F. Thompson, and D. Menemenlis. Ocean submesoscales as a key component of the global heat budget. Nature Communications, 9(1):1-8, 2018.

[73] M. Sun, F. Tian, Y. Liu, and G. Chen. An improved automatic algorithm for global eddy tracking using satellite altimeter data. Remote Sensing, 9(3):1-18, 2017.

[74] N. Tarshish, R. Abernathey, C. Zhang, C. O. Dufour, I. Frenger, and S. M. Griffies. Identifying Lagrangian Coherent Vortices in a Mesoscale Ocean Model. Ocean Modelling, 130:15-28, 2018.

[75] J. Theiss. Equatorward Energy Cascade, Critical Latitude, and the Predominance of Cyclonic Vortices in Geostrophic Turbulence. Journal of Physical Oceanography, 34:1663-1678, 2004. 
[76] L. N. Thomas, A. Tandon, and A. Mahadevan. Submesoscale processes and dynamics. Journal of Geophysical Research, pages 17 - 38, 2008.

[77] H. S. Torres, P. Klein, D. Menemenlis, B. Qiu, Z. Su, J. Wang, S. Chen, and L. L. Fu. Partitioning Ocean Motions Into Balanced Motions and Internal Gravity Waves: A Modeling Study in Anticipation of Future Space Missions. Journal of Geophysical Research: Oceans, 123(11):8084-8105, 2018.

[78] R. Tulloch, J. Marshall, C. Hill, and K. S. Smith. Scales, Growth Rates, and Spectral Fluxes of Baroclinic Instability in the Ocean. Journal of Physical Oceanography, 41(6):1057-1076, 2011.

[79] R. Tulloch, J. Marshall, and K. S. Smith. Interpretation of the propagation of surface altimetric observations in terms of planetary waves and geostrophic turbulence. Journal of Geophysical Research: Oceans, 114(2):1-11, 2009.

[80] C. Ubelmann, P. Klein, and L. L. Fu. Dynamic interpolation of sea surface height and potential applications for future high-resolution altimetry mapping. Journal of Atmospheric and Oceanic Technology, 32(1):177-184, 2015.

[81] G. Vallis. Atmospheric and Oceanic Fluid Dynamics: Fundamentals and Large-scale Circulation. Cambridge: Cambridge University Press, 2006.

[82] A. B. Villas Bôas, O. T. Sato, A. Chaigneau, and G. P. Castelão. The signature of mesoscale eddies on the air-sea turbulent heat fluxes in the South Atlantic Ocean. Geophysical Research Letters, 42:1856 - 1862, 2015.

[83] D. Walters, A. Baran, I. Boutle, M. Brooks, P. Earnshaw, J. Edwards, K. Furtado, P. Hill, A. Lock, J. Manners, C. Morcrette, J. Mulcahy, C. Sanchez, C. Smith, R. Stratton, W. Tennant, L. Tomassini, K. Van Weverberg, S. Vosper, M. Willett, J. Browse, A. Bushell, M. Dalvi, R. Essery, N. Gedney, S. Hardiman, B. Johnson, C. Johnson, A. Jones, G. Mann, S. Milton, H. Rumbold, A. Sellar, M. Ujiie, M. Whitall, K. Williams, and M. Zerroukat. The Met Office Unified Model Global Atmosphere 7.0/7.1 and JULES Global Land 7.0 configurations. Geoscientific Model Development Discussions, in review, 2017.

[84] S. Waterman and B. J. Hoskins. Eddy shape, orientation, propagation, and mean flow feedback in western boundary current jets. Journal of Physical Oceanography, 43(8):1666-1690, 2013.

[85] K. D. Williams, D. Copsey, E. W. Blockley, A. Bodas-Salcedo, D. Calvert, R. Comer, P. Davis, T. Graham, H. T. Hewitt, R. Hill, P. Hyder, S. Ineson, T. C. Johns, A. B. Keen, R. W. Lee, A. Megann, S. F. Milton, J. G. Rae, M. J. Roberts, A. A. Scaife, R. Schiemann, D. Storkey, L. Thorpe, I. G. Watterson, D. N. Walters, A. West, R. A. Wood, T. Woollings, and P. K. Xavier. The Met Office Global Coupled Model 3.0 and 3.1 (GC3.0 and GC3.1) Configurations. Journal of Advances in Modeling Earth Systems, 10(2):357$380,2018$. 
[86] P. J. Wolfram and T. D. Ringler. Computing eddy-driven effective diffusivity using Lagrangian particles. Ocean Modelling, 118:94-106, 2017.

[87] X. Yu, A. C. Naveira Garabato, A. P. Martin, D. G. Evans, and Z. Su. Windforced symmetric instability at a transient midocean front. Geophysical Research Letters, pages 1-11, 2019.

[88] X. Zhai, H. L. Johnson, and D. P. Marshall. Significant sink of ocean-eddy energy near western boundaries. Nature Geoscience, 3(9):608-612, 2010. 


\begin{tabular}{|c|c|c|c|c|c|c|c|c|}
\hline & Type & $>1 \mathrm{wk}$ & $>4 \mathrm{wks}$ & $>16 \mathrm{wks}$ & $>26 w k s$ & $>40 \mathrm{wks}$ & $>52 \mathrm{wks}$ & $>78 \mathrm{wks}$ \\
\hline \multirow[t]{3}{*}{ EP } & A & 143,944 & 29,721 & 2,099 & 495 & 96 & 41 & 13 \\
\hline & $\mathrm{C}$ & 135,892 & 24,943 & 1,744 & 378 & 58 & 13 & 1 \\
\hline & & & $19.5 \%$ & $1.4 \%$ & $0.31 \%$ & $0.06 \%$ & $0.02 \%$ & $0.005 \%$ \\
\hline \multirow[t]{3}{*}{ ER } & A & 202,639 & 45,595 & 4,412 & 1,333 & 386 & 190 & 82 \\
\hline & $\mathrm{C}$ & 205,633 & 41,642 & 4,003 & 1,240 & 346 & 155 & 33 \\
\hline & & & $21.4 \%$ & $2.1 \%$ & $0.63 \%$ & $0.18 \%$ & $0.08 \%$ & $0.03 \%$ \\
\hline \multirow[t]{3}{*}{ Obs } & A & 355,221 & 73,683 & 5,021 & 1,276 & 306 & 115 & 32 \\
\hline & $\mathrm{C}$ & 334,599 & 64,064 & 3,874 & 933 & 206 & 70 & 11 \\
\hline & & & $20.0 \%$ & $1.3 \%$ & $0.3 \%$ & $0.07 \%$ & $0.03 \%$ & $0.006 \%$ \\
\hline
\end{tabular}

Table 1: Number of eddies detected with lifetimes longer than 1, 4, 16, 26, 40, 52 and 78 weeks for the eddypermitting simulation $E P_{\text {sim }}$, the eddy-resolving simulation $E R_{\text {sim }}$, and the AVISO gridded satellite altimetry product (Obs). The counts are scaled to 10 years and separated for cyclonic $(C)$ and anti-cyclonic $(A)$ eddies. For each data set, the third line (in italic) indicates the survival rate, i.e. the ratio (expressed in \%) between the total number of eddies with a given lifetime and the total number of eddies with lifetime longer than 1 week. 

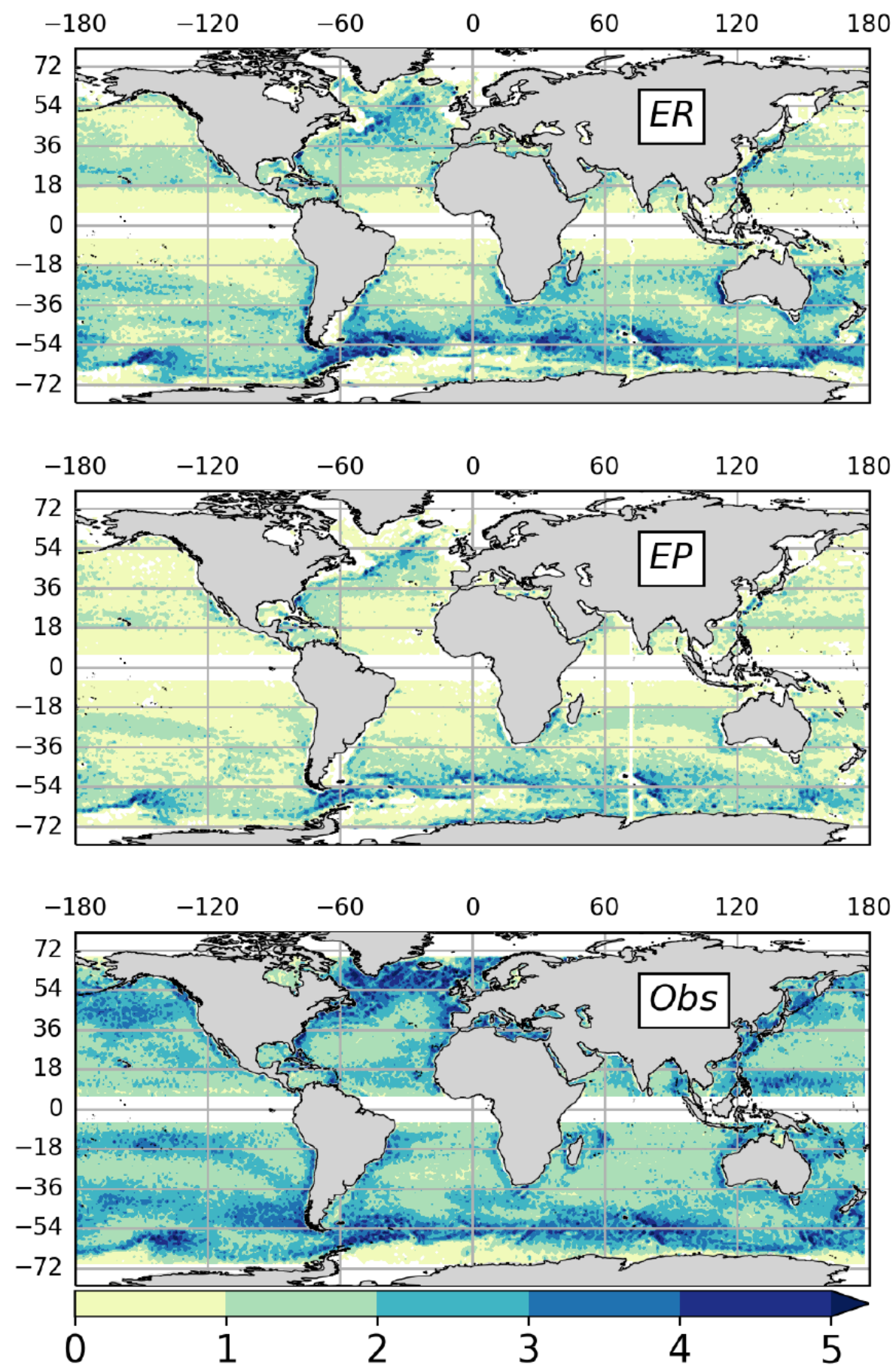

Figure 1: Eddy genesis (number of eddies per year) for eddies lasting longer than 1 week (binned to $1^{\circ} \times 1^{\circ}$ boxes). 

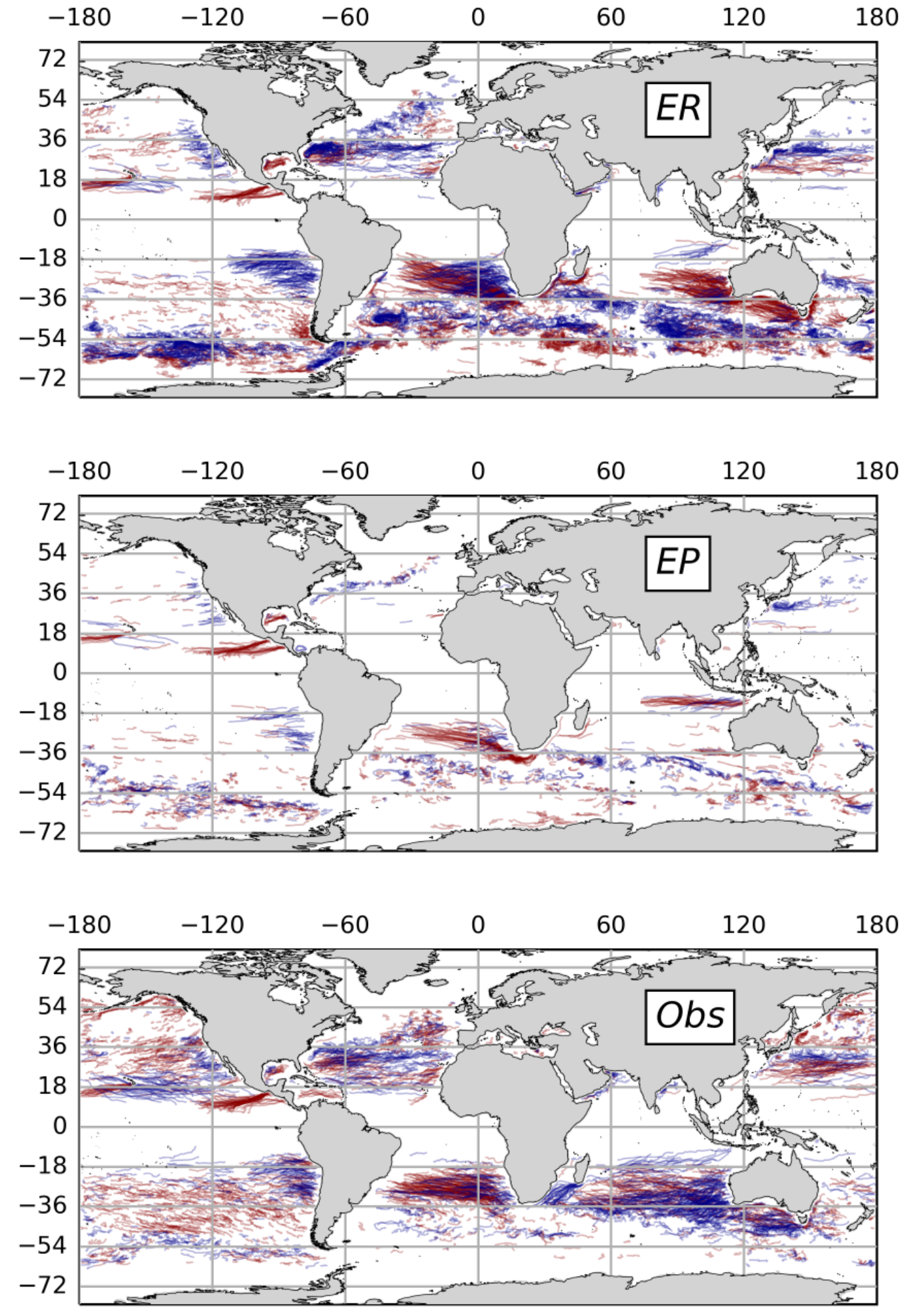

Figure 2: Eddy trajectories lasting longer than 6 months over 20 years. Anti-cyclonic (cyclonic) eddies are shown in red (blue). 

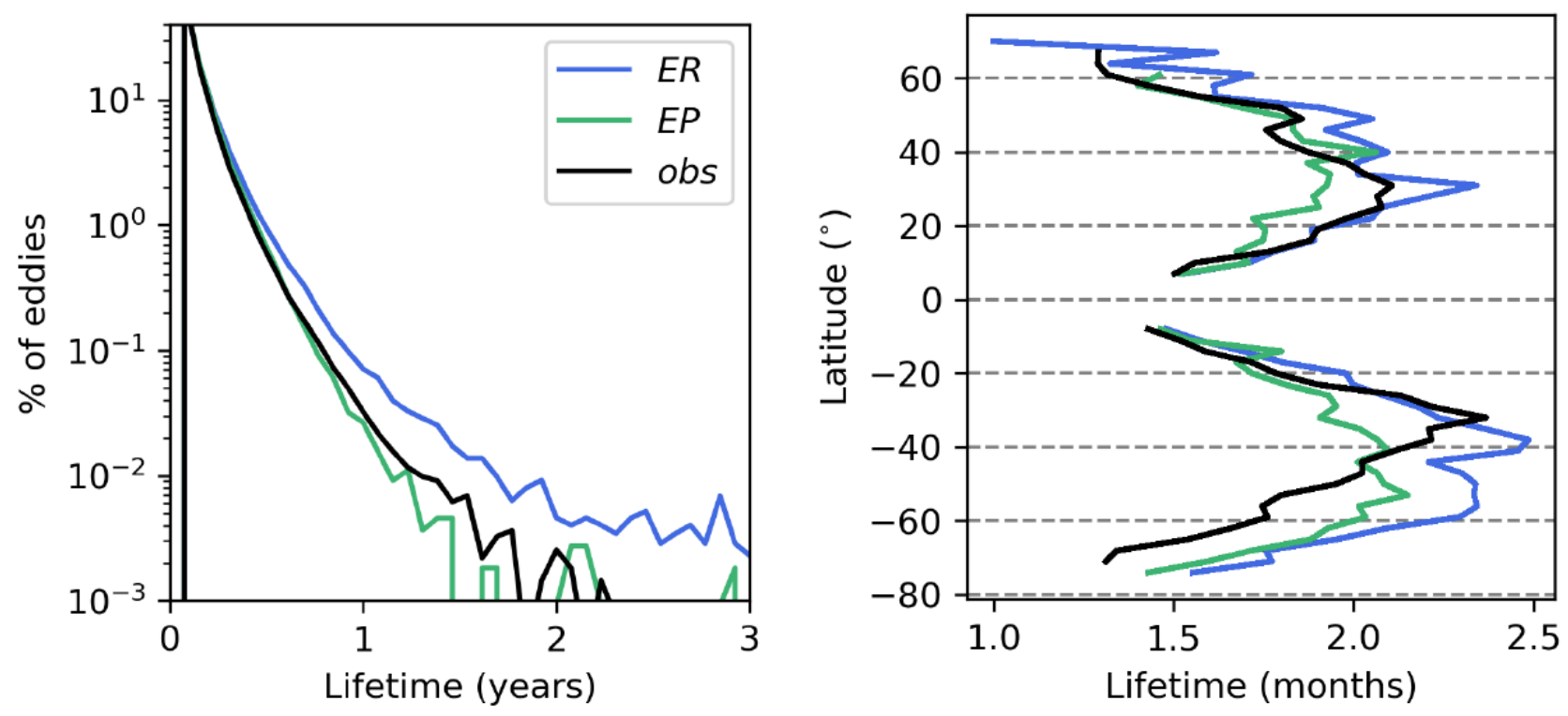

Figure 3: Probability density function of eddy lifetime (left) and zonal average of eddy lifetime (right). Both plots use eddies with lifetimes longer than 1 month. 

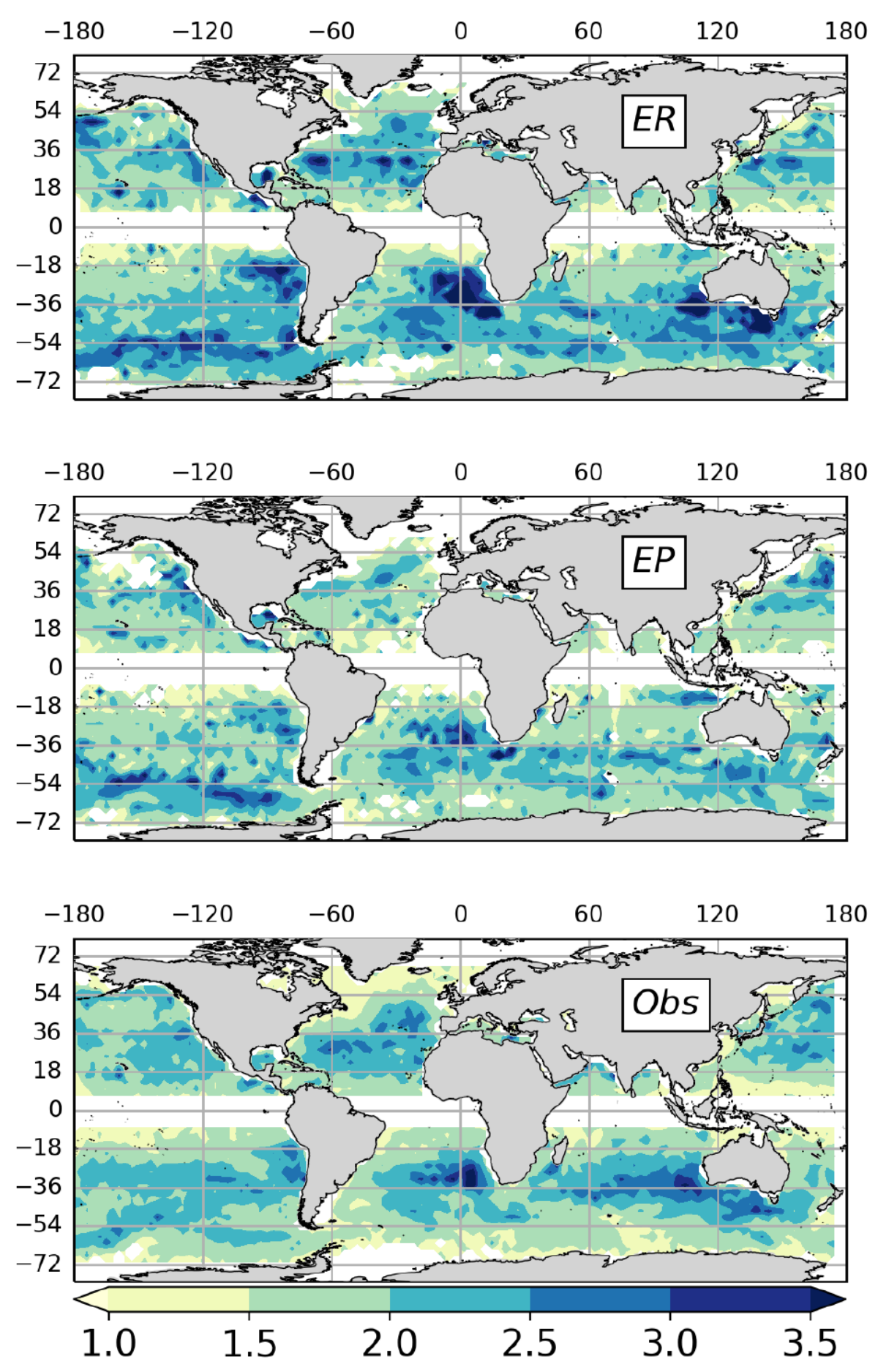

Figure 4: Eddy lifetimes (in months) mapped to genesis location and binned to $3^{\circ} \times 3^{\circ}$ grid boxes. All plots use eddies with lifetimes longer than 1 month. 

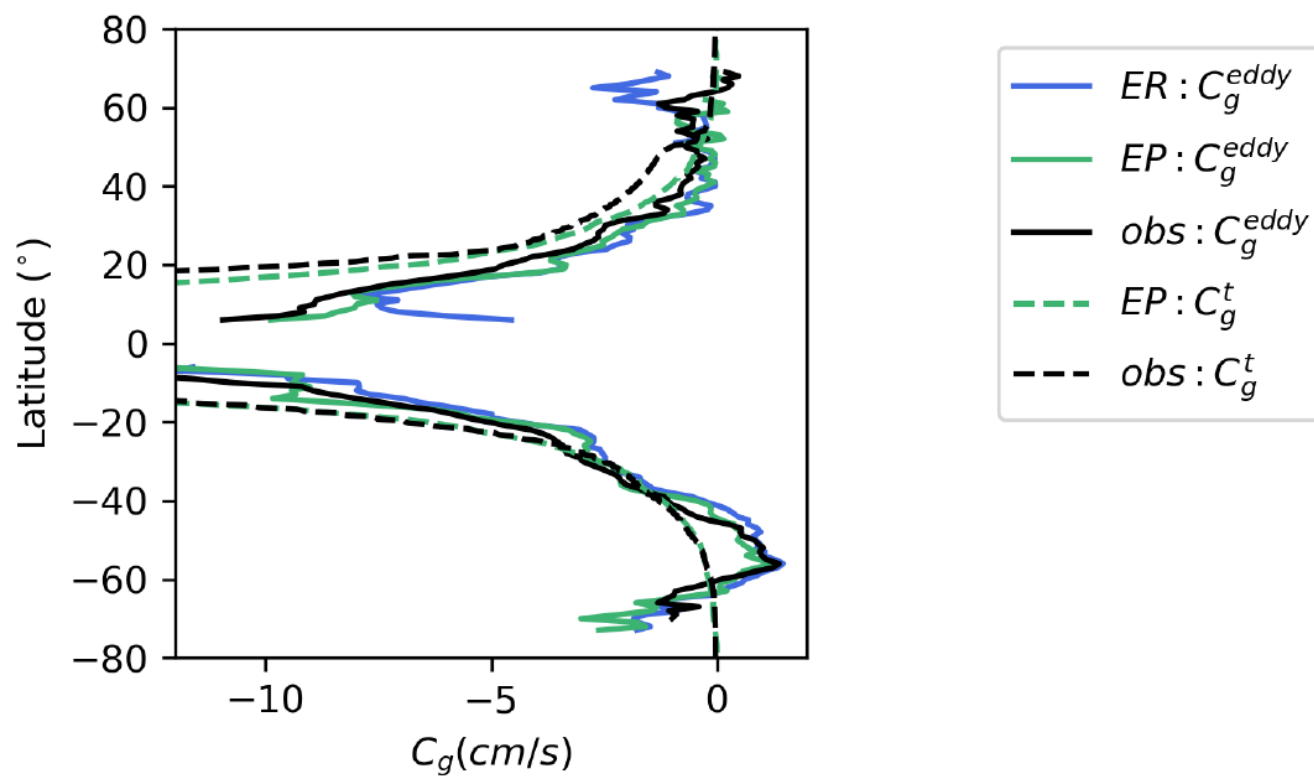

Figure 5: Zonal average of zonal propagation velocity $\left(\mathrm{cm} \mathrm{s}^{-1}\right)$ from tracked eddies, $C_{g}^{e d d y}$. Dotted lines are the theoretical long-wave baroclinic Rossby Wave speed $C_{g}^{t}$ for observations (black) and $E P_{\text {sim }} / E R_{\text {sim }}$ (green).
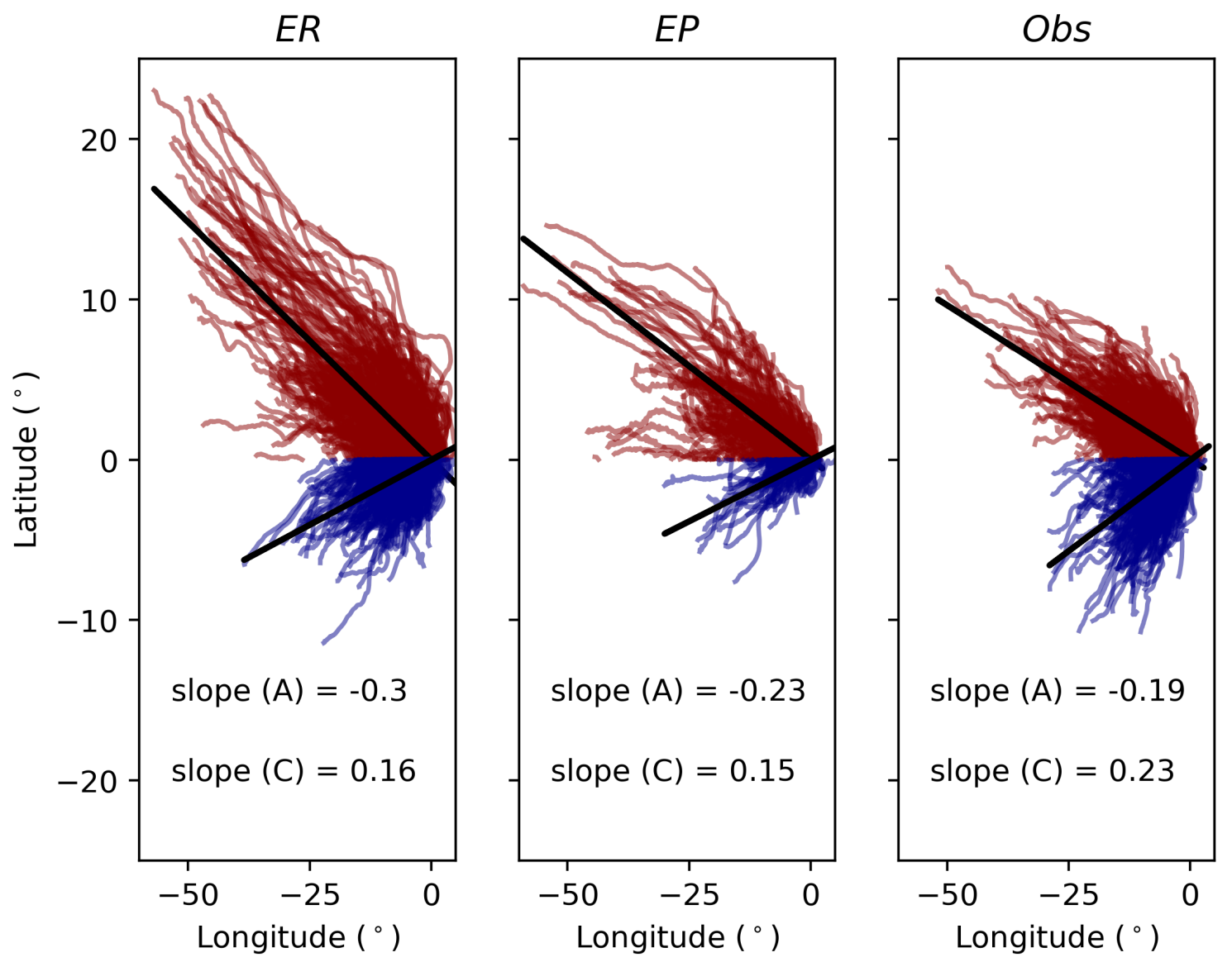

Figure 6: Co-located trajectories of westward-propagating eddies lasting longer than 6 months for ER, EP and observations. Anti-cyclonic eddies (A) are plotted in red, cyclonic eddies $(C)$ are in blue and the regression coefficients for each are given on each subplot. 

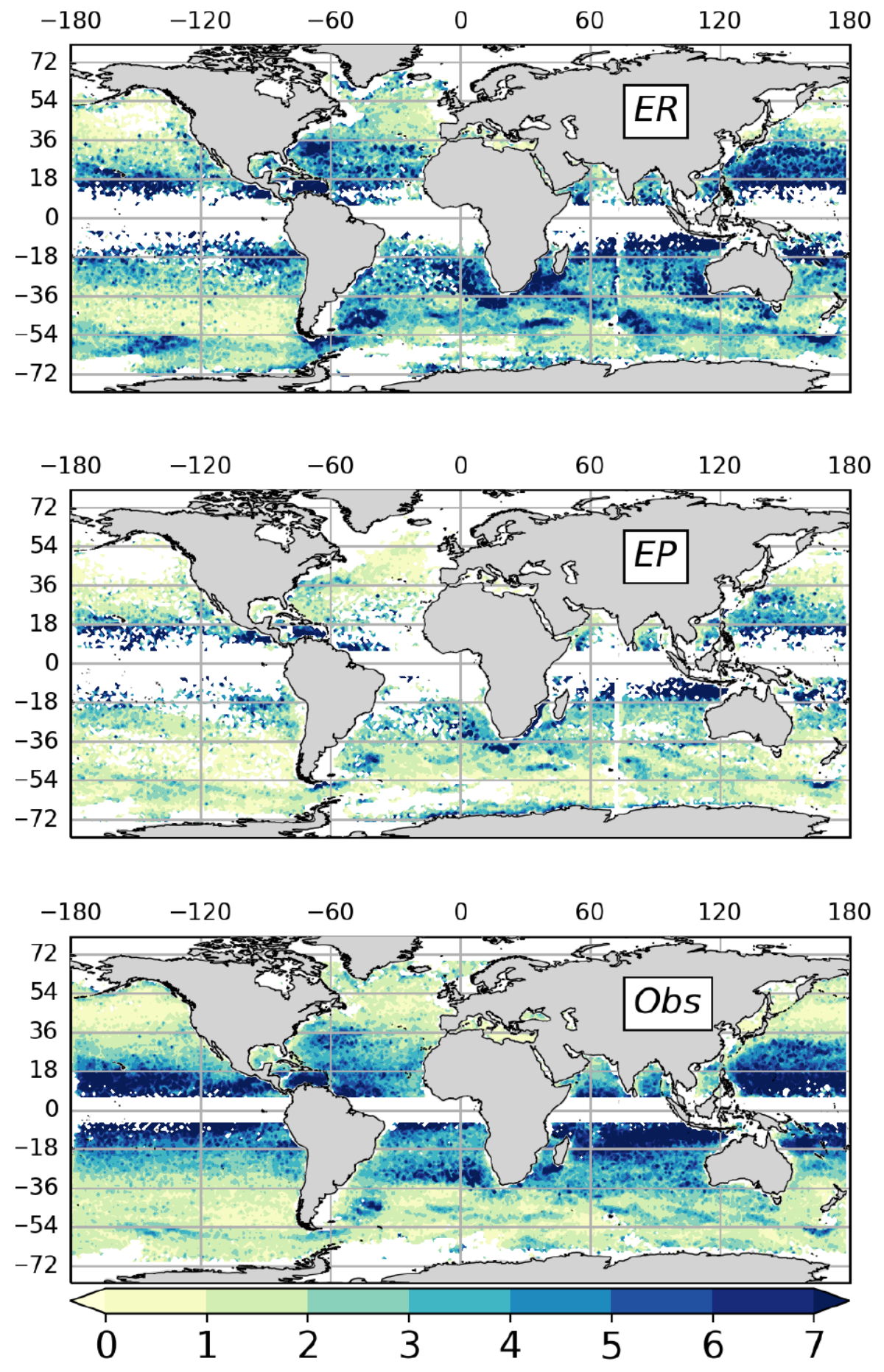

Figure 7: 20-year average of the ratio $D / \overline{L_{e f f}}$ where $D$ is net zonal zonal distance covered by an eddy and $\overline{L_{e f f}}$ its lifetime-averaged effective radius. The ratios are mapped to genesis locations and binned to $1^{\circ} \times 1^{\circ}$ boxes. 

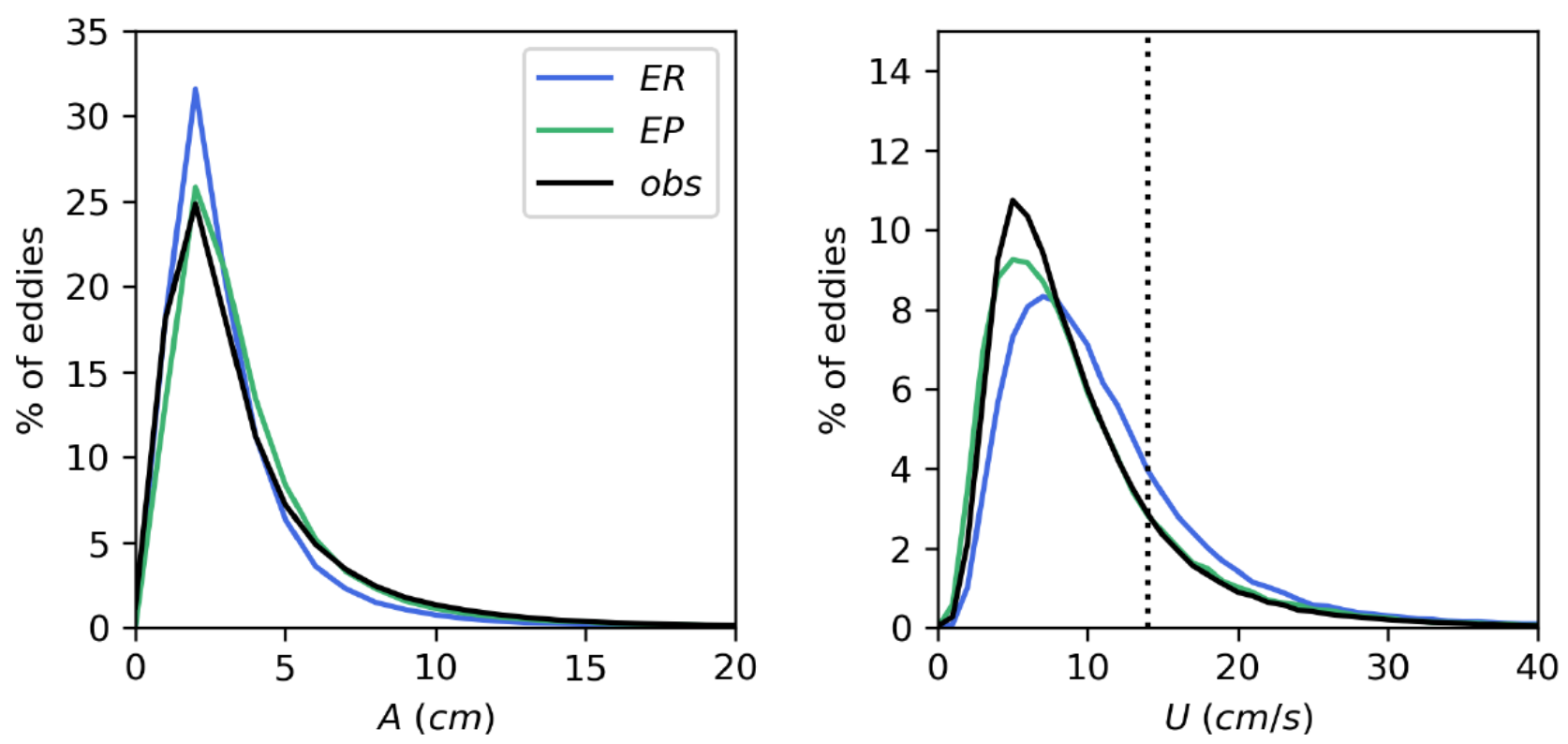

Figure 8: Probability density functions of the lifetime-averaged amplitude A (left) and rotational velocity $U$ (right) of eddies longer than 1 month (with $1 \mathrm{~cm}$ and $1 \mathrm{~cm} \mathrm{~s}^{-1}$ bins). The black dotted line is plotted at $14 \mathrm{~cm} \mathrm{~s}^{-1}$.
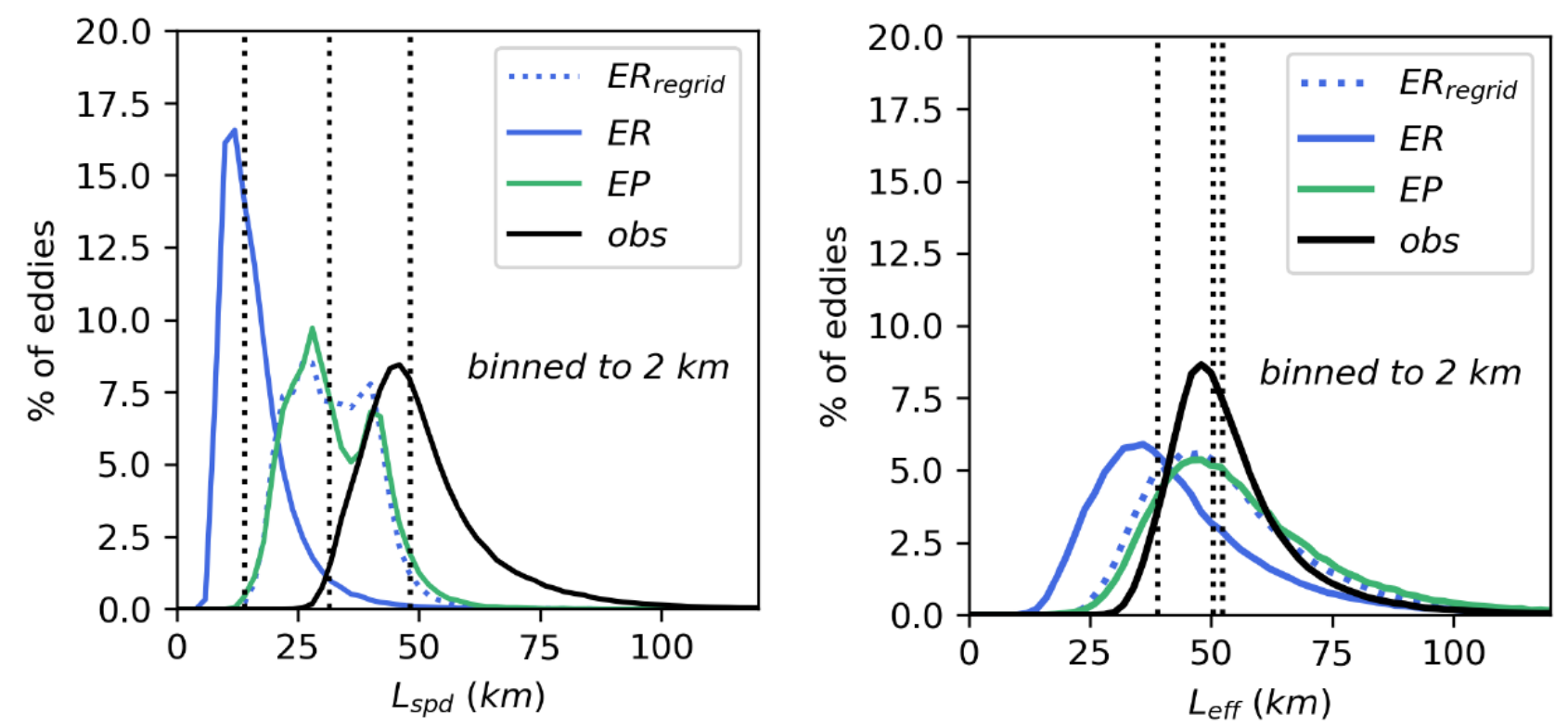

Figure 9: Probability density functions (pdfs) of the lifetime-averaged $L_{s p d}$ and $L_{\text {eff }}$ : a normalized pdf on a linear scale with $2 \mathrm{~km}$ bins. The black dotted lines are plotted at the medians for each resolution: the median values for $L_{s p d} / L_{\text {eff }}$ are $48 \mathrm{~km} / 50 \mathrm{~km}, 32 \mathrm{~km} / 52 \mathrm{~km}$ and $14 \mathrm{~km} / 39 \mathrm{~km}$ for observations, $E P_{\text {sim }}$ and $E R_{\text {sim }}$, respectively. 

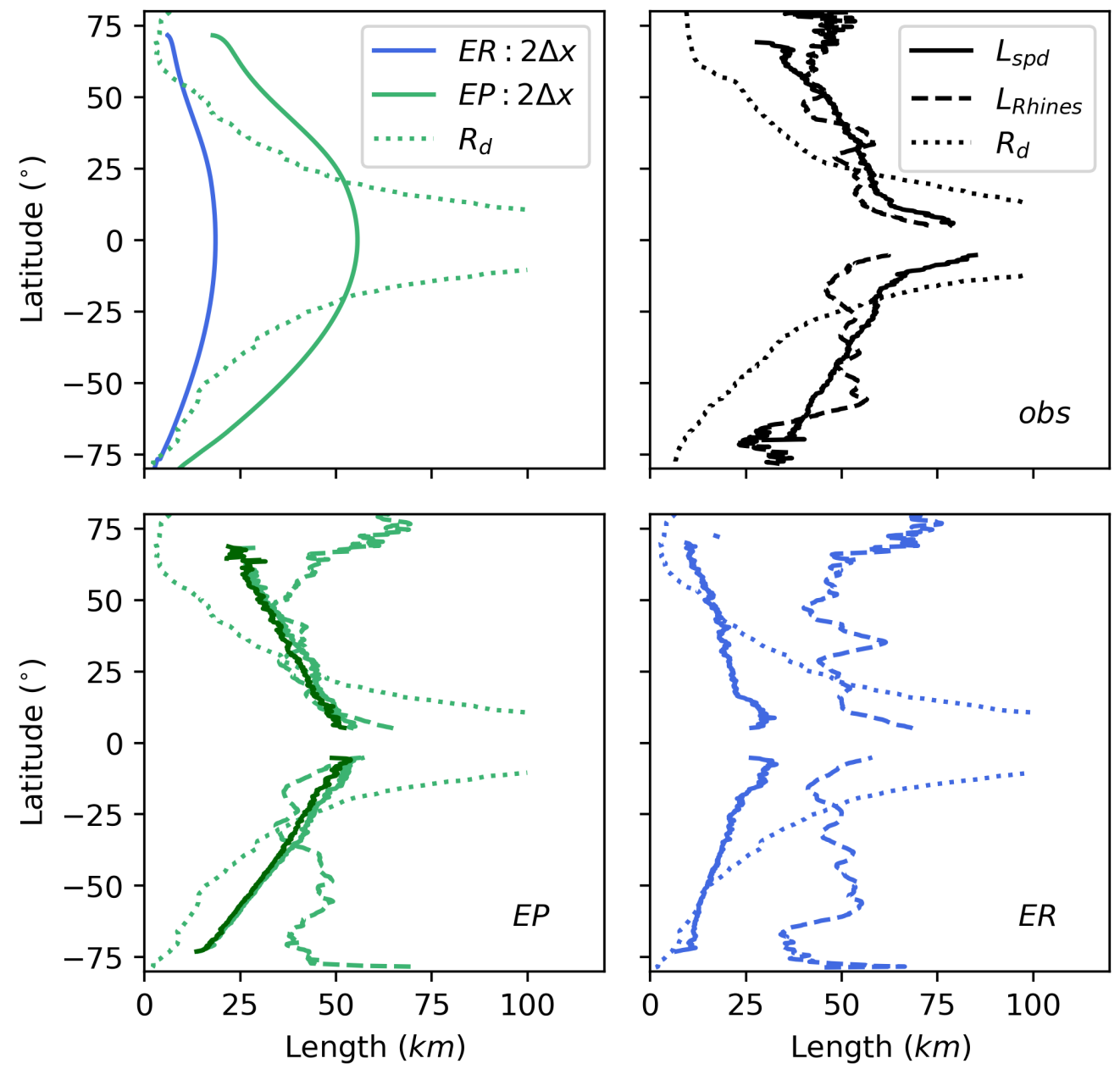

Figure 10: (top left) Zonal average of the observed Rossby radius of deformation $R_{d}$ and $2 \Delta x$ for EP and $E R$. (top right and lower subplots) Zonal average of $L_{\text {spd }}$ (solid lines), the Rossby radius of deformation $\left(R_{d}\right.$, dotted line) and the Rhines Scale ( $L_{\text {Rhines }}$, dashed line) for observations (black), EP sim (green) and $E R_{\text {sim }}$ (blue). The zonal average of $L_{s p d}$ for $E R_{\text {regrid }}$ is plotted in dark green. 

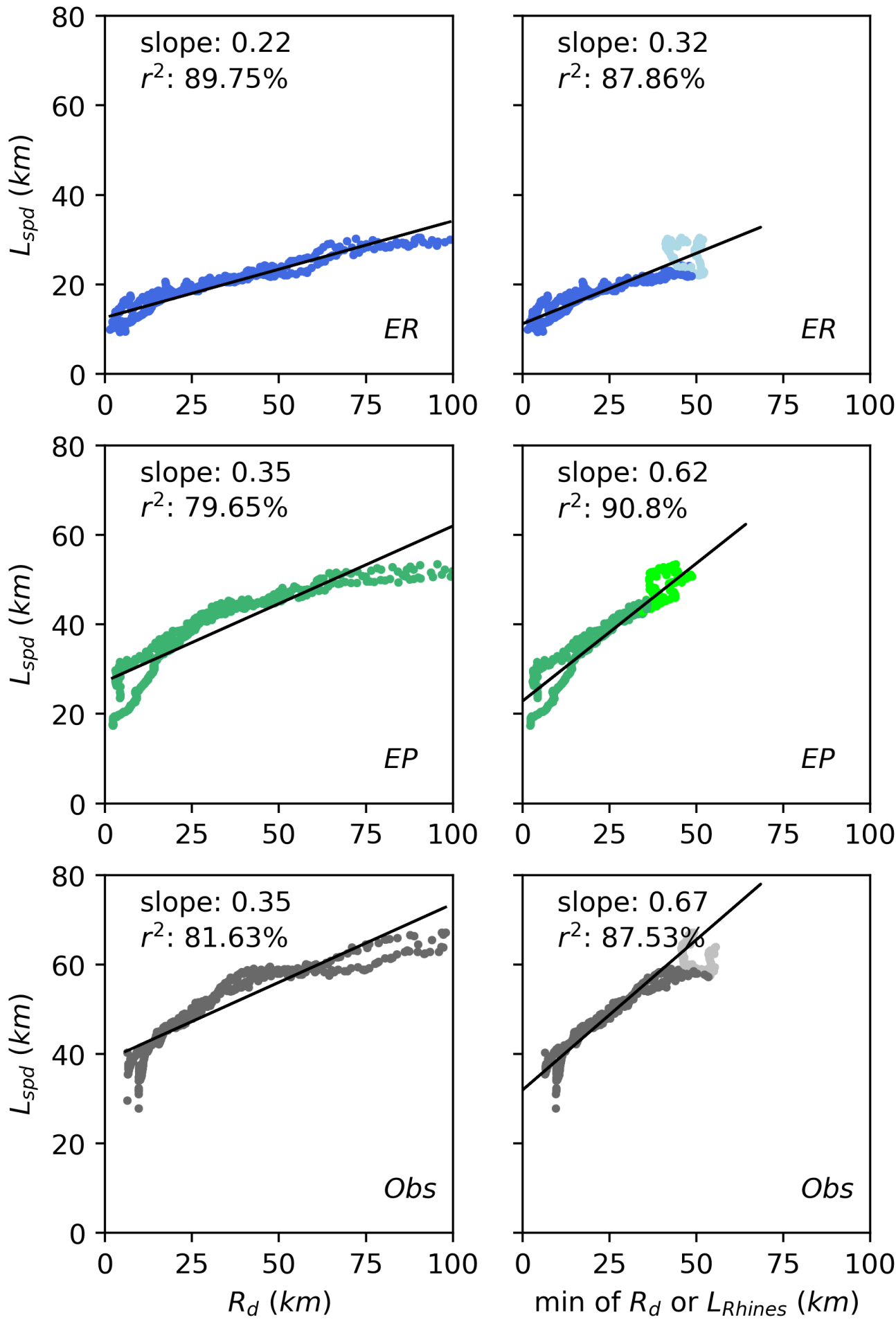

Figure 11: $L_{\text {spd }}$ compared to $R_{d}$ (left) and to the minimum of $R_{d}$ and $L_{r h i n e s}$ (right). The data is global after zonally averaging. The linear regression line is plotted in black. In the right panels, the shade of colour indicates whether the minimum is reached with $R_{d}$ (darker shade) or $L_{R h i n e s}$ (lighter shade). EP is plotted in blue, EP in green and observations are plotted in grey. 

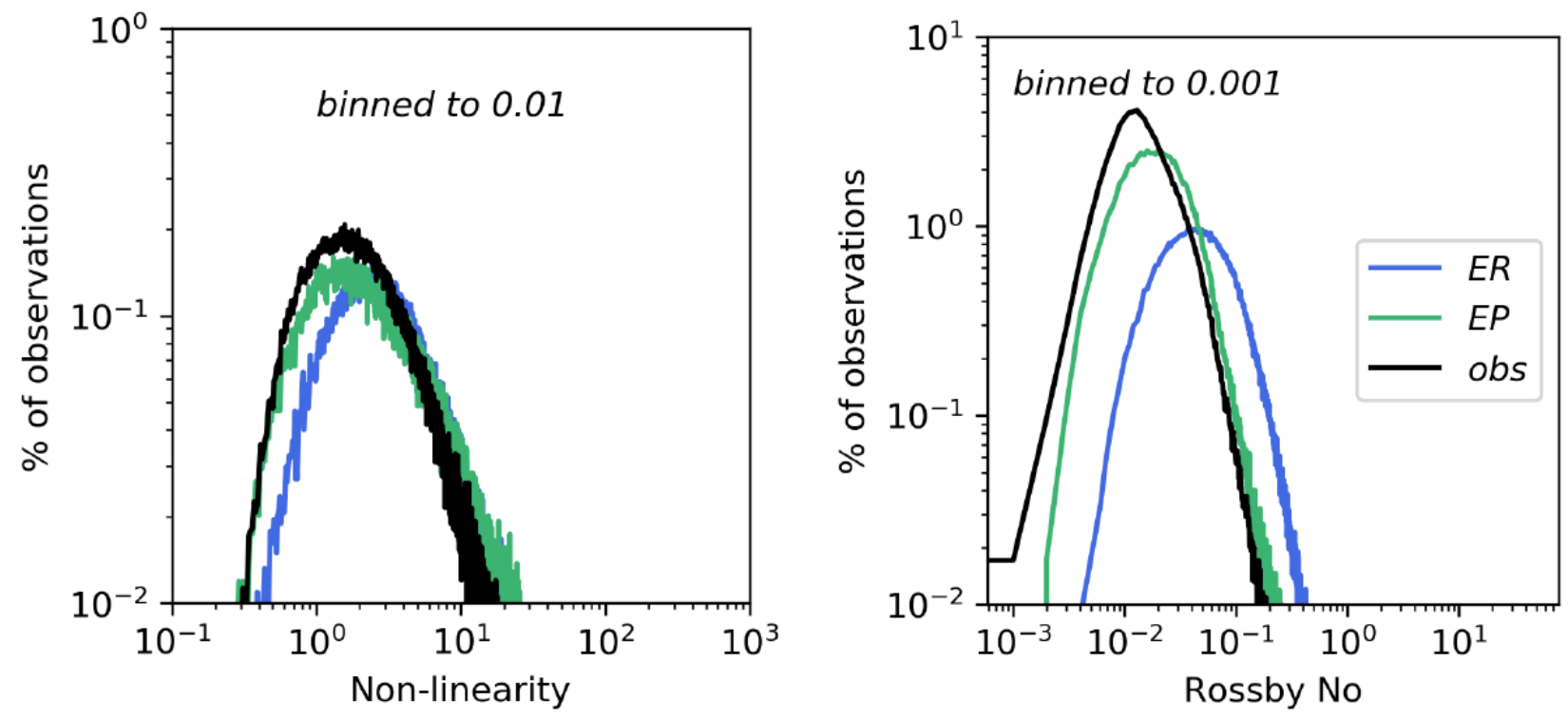

Figure A1: Probability density functions of (left) the non-linearity parameter $r$ and (right) the Rossby number $R_{0}$. 

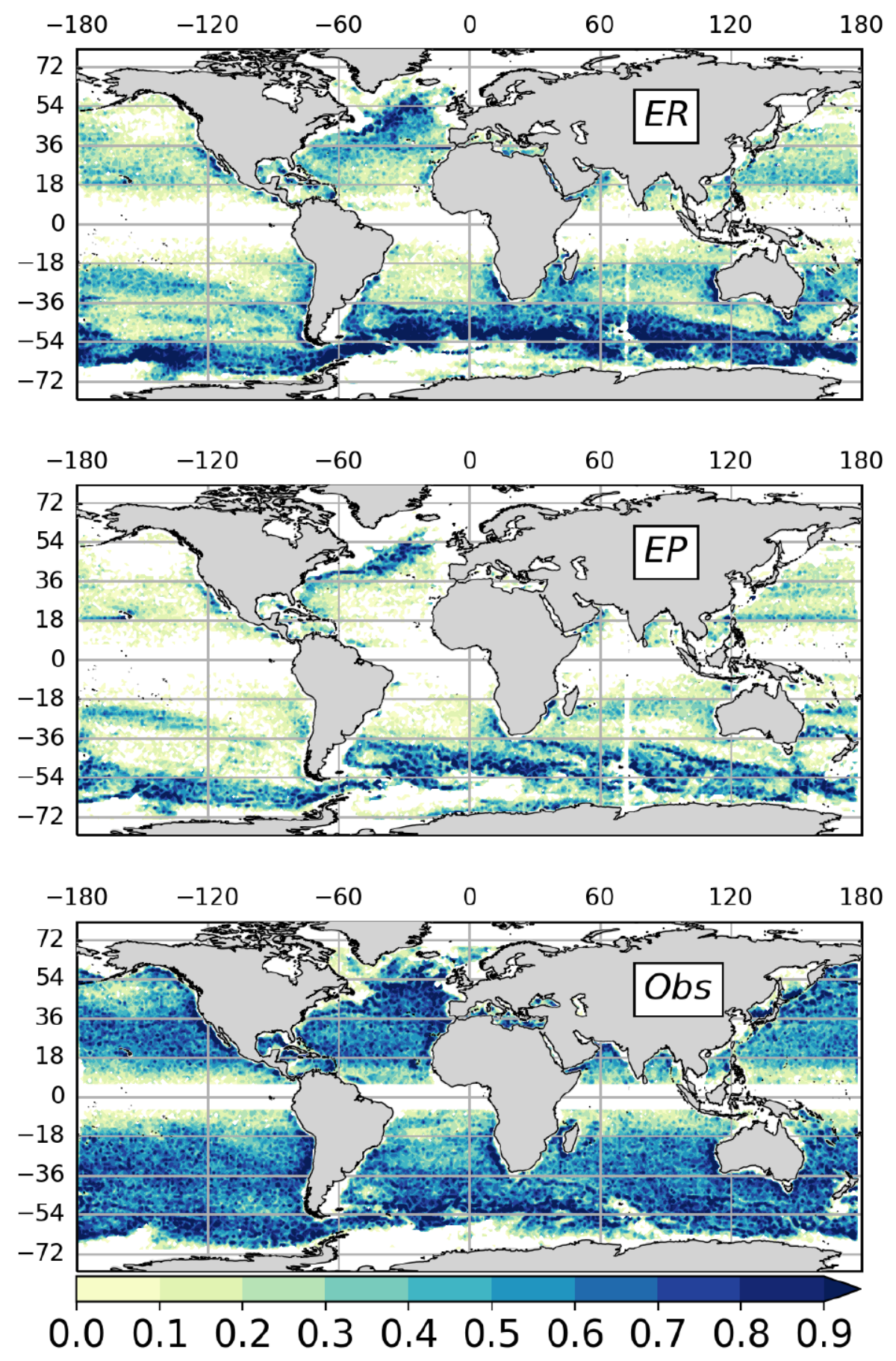

Figure A2: Eddy genesis (number of eddies per year) for eddies lasting longer than 1 month (binned to $1^{\circ} \times 1^{\circ}$ grid boxes). 

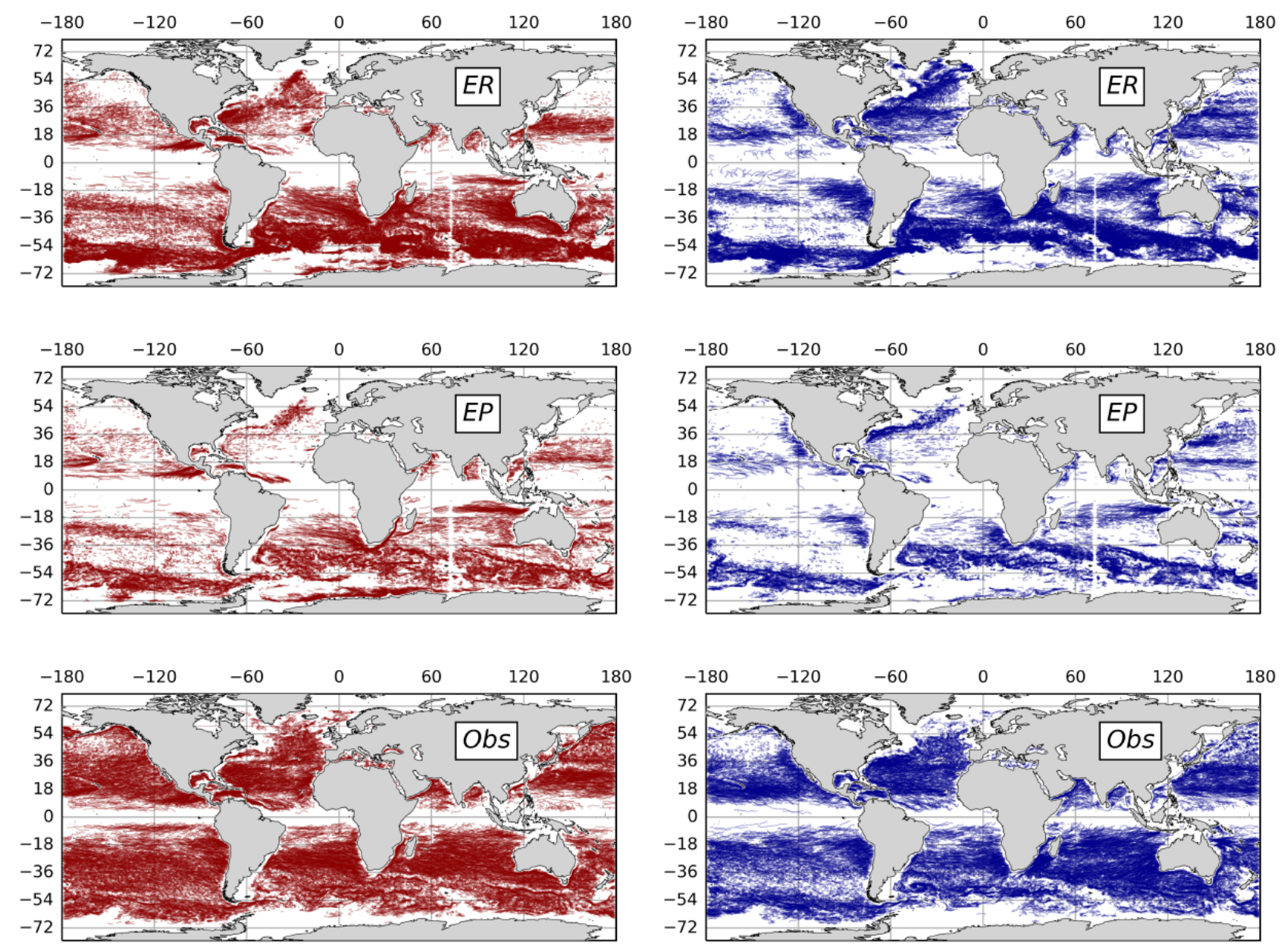

Figure A3: Eddy trajectories lasting longer than 2 months over 20 years. Anti-cyclonic eddies (left) are shown in red and cyclonic eddies (right) are in blue.
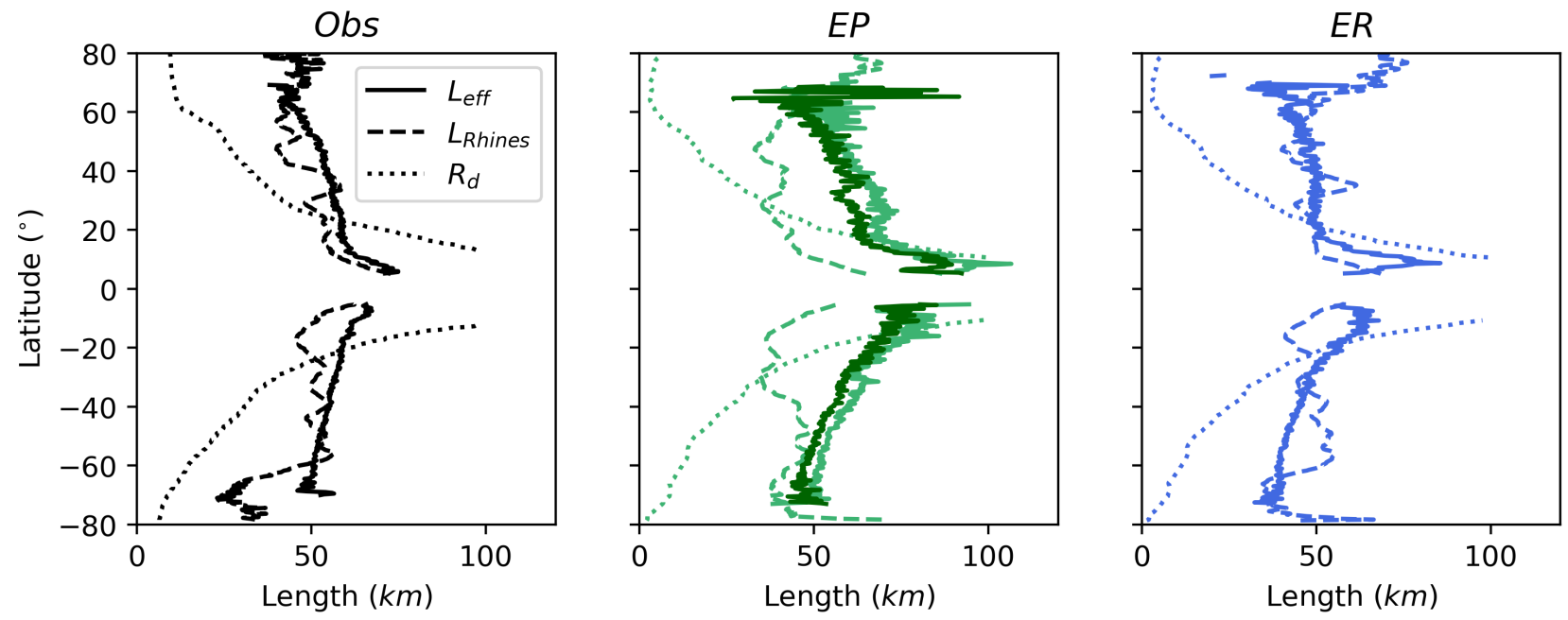

Figure A4: A repeat of the zonal average shown in Fig. 10 for $L_{e} f f$ (solid lines) against the Rossby radius of deformation $\left(R_{d}\right.$, dotted line) and the Rhines scale ( $L_{\text {Rhines, }}$, dashed line). Observations are plotted in black, $E P$ is in green and ER in blue. The zonal average of $L_{\text {spd }}$ for $E R_{\text {regrid }}$ is plotted in dark green. 

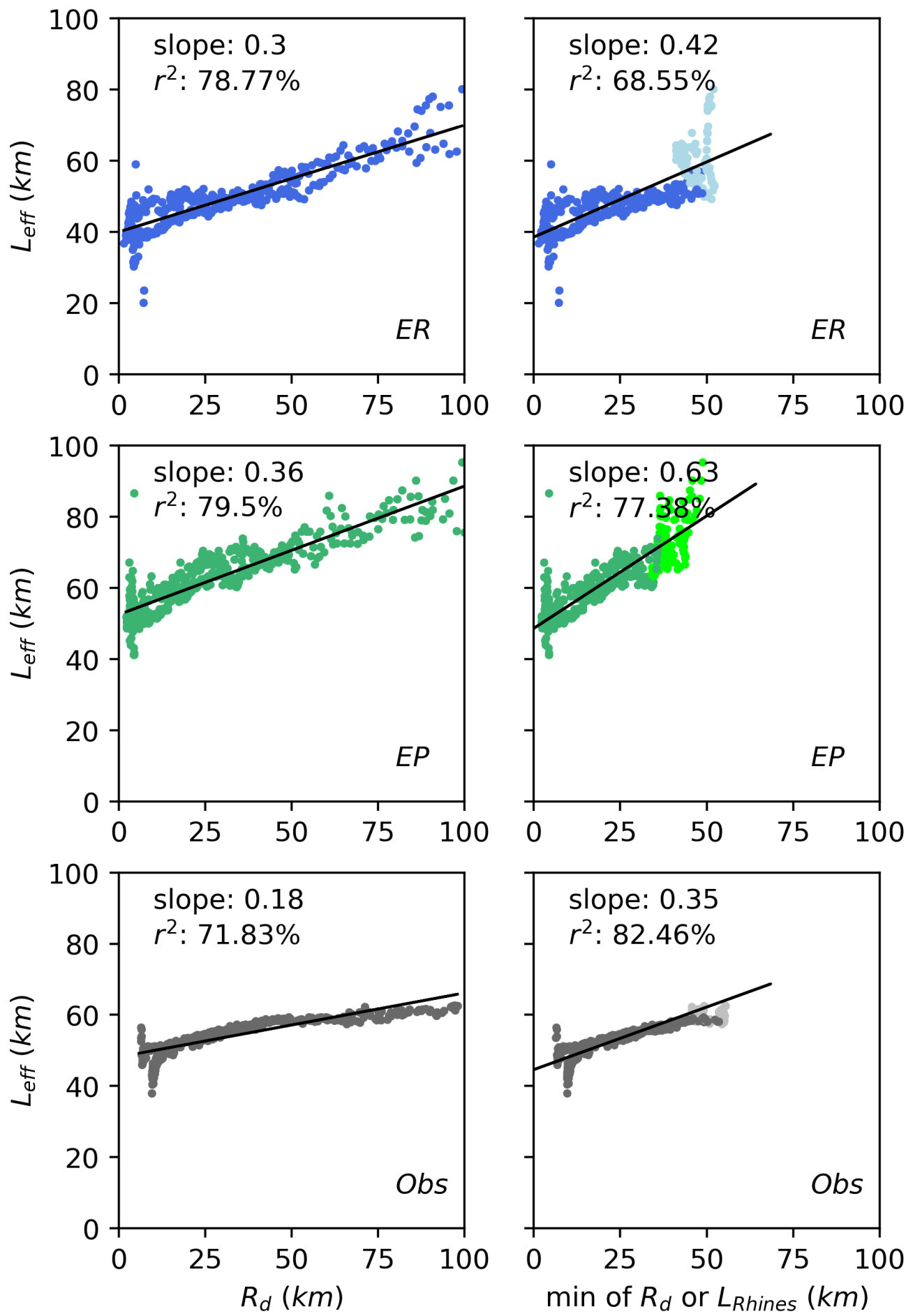

Figure A5: Same as Fig. 11 but for the effective radius $L_{\text {eff }}$. 

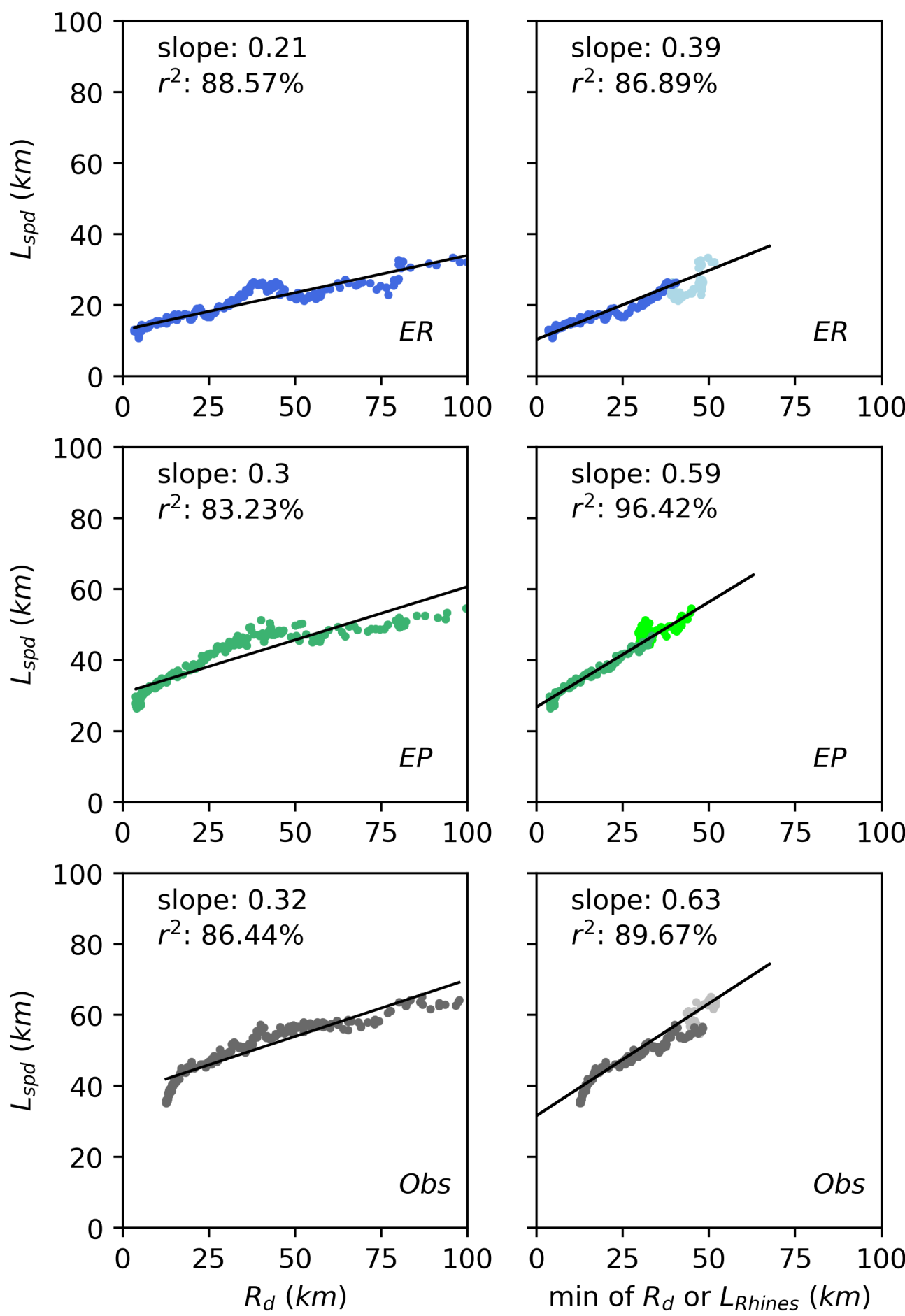

Figure A6: Same as Fig. 11 but for the North Atlantic only $\left(0-70^{\circ} \mathrm{N}, 80^{\circ} \mathrm{W}-10^{\circ} \mathrm{E}\right)$ for comparison with [22]. 